
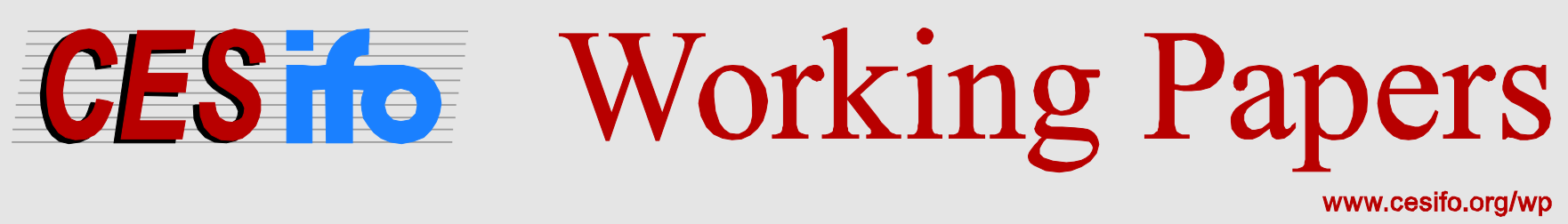

\title{
Productivity, Price- and Wage-Markups: An Empirical Analysis of the Dutch Manufacturing Industry
}

\author{
Sara Amoroso \\ Bertrand Melenberg \\ Joseph Plasmans \\ Mark Vancauteren
}

CESIFO WORKING PAPER NO. 5273

CATEGORY 11: INDUSTRIAL ORGANISATION

MARCH 2015

An electronic version of the paper may be downloaded

- from the SSRN website:

- from the RePEc website:

- from the CESifo website:

WWW.SSRN.com

Www.RePEc.org

www.CESifo-group.org/wp

\section{CESifo}




\title{
Productivity, Price- and Wage-Markups: An Empirical Analysis of the Dutch Manufacturing Industry
}

\begin{abstract}
This paper examines the interaction between productivity growth, firms' monopolistic market power, and workers' wage bargaining power. Our study contributes to several strands of literatures. First, we examine a monopolistic framework which accounts for wage bargaining. In addition to the other studies, along with the parameters characterizing a production function and the price-cost margins, we derive a measure of wage markup without relying on trade union participation data, and we study the correlation of the estimated parameters and markups with the firm-level productivity growth. Second, the paper contributes to literature on the structural identification of production functions in two ways. As a first step, it reviews the different estimation techniques that have been tackling the endogeneity issues concerning the simultaneity, the omitted output price, and the collinearity among input factors of production. Additionally, we propose an identification strategy that relies on the presence of imperfect competition in the flexible input market, namely, the labor market.
\end{abstract}

JEL-Code: L100, D220, D240, J510.

Keywords: price-cost margin, trade unions, identification, production functions, panel data.

\author{
Sara Amoroso* \\ JRC European Commission \\ Seville / Spain \\ sara.amoroso@ec.europa.eu
}

Joseph Plasmans

University of Antwerp

Antwerpen / Belgium

joseph.plasmans@ua.ac.be

\author{
Bertrand Melenberg \\ CentER, Tilburg University \\ Tilburg / The Netherlands \\ b.melenberg@uvt.nl
}

\author{
Mark Vancauteren \\ Hasselt University \\ Diepenbeek / Belgium \\ mark.vancauteren@uhasselt.be
}

*corresponding author

We thank the National Science Foundation of the Netherlands (NWO) for financial support (within the framework of the Dynamism of Innovation research project). We also thank Sabien Dobbelaere (VU University Amsterdam), Florin Maican (Research Institute of Industrial Economics), and Tobias Klein (Tilburg University), for the helpful comments on an earlier version of the manuscript. We thank Peter Kort (Tilburg University), Bert Balk (Erasmus University Rotterdam and Statistics Netherlands), and the participants of the 2012 Royal Economic Society Conference at the University of Cambridge for fruitful discussions. 


\section{Introduction}

Theoretically, the presence of trade unions is arising from the asymmetry in contracting between individual workers and employers. The alternative to a unionized labor market is one characterized by a perfectly competitive structure that ensures the workers may choose whether or not to work, by comparing the given perfectly competitive wage with the marginal utility of not working. However, the absence of unions may not correspond to an underlying perfectly competitive situation in the labor market. Instead, it may lead to the abuse of market power on the labor demand side in the form of monopsony, that is, a situation in which there is only one buyer of the labor services. Additionally, firms in some industries may pay workers more than the going market rate to attract new ones. Hence, policy makers, whose objective is to establish and maintain a perfectly competitive labor market, seek for policies designed to free up the demand side of the market. The presence of unions in such circumstances may offer a second-best alternative to free competition. Moreover, the potential benefits associated with the presence of unions in the form of "voice"1 should be counted against the costs due to misallocation effects. As a matter of fact, unions can contribute positively to the productivity of a firm, by facilitating the communication between labor force and management, drawing the attention of the latter to changes in working methods or production techniques that may be beneficial to both parties.

Despite the abundant theoretical arguments for both positive and negative effects of trade unions on productivity, data and empirical evidence are generally lacking. In particular, data for unionized versus non-unionized labor are scarce and highly aggregated 2 In this paper, we propose a methodology to evaluate the impact of trade unions on productivity growth that does not rely on individual worker data, but on firm-level data. In particular, we rely on the framework of production functions to estimate simultaneously price-cost markups, wage markups, and productivity growth. Our study is to some extent related to the previous work of Dobbelaere (2004); Dobbelaere and Mairesse (2013) which consider imperfections in both product and labor markets.

Within the production function framework, the econometric literature has focused on some important econometric issues that need to be dealt with when estimating such functions at the firm level. A first econometric issue, broadly known as simultaneity, is the potential correlation between unobserved productivity shocks and the input factors. A second problem arises from measurement errors in output or inputs. Typically, we observe deflated measures in place of the original physical quantities. This leads to two kinds of problems: the first is associated with endogeneity and the second concerns the correct identification of firm-specific productivity measures. The endogeneity problem is due to the potential correlation between unobservable firm-level (input and output) price variations and input choices (Klette and Griliches, 1996; Ornaghi, 2008; De Loecker, 2011).

\footnotetext{
${ }^{1}$ A source of empowerment through which the employees can express their grievances without having to leave the firm (Aidt and Tzannatos, 2008)

2 http://www.ilo.org/ilostat/
} 
The productivity measurement identification issue derives from the fact that neglecting the variation in factor prices leads to the estimation of performance measures that are indices of revenue per unit input expenditure, rather than measures of efficiency (Katavama et al., 2009). Another problem concerns the highly correlated factor inputs. In fact, if inputs are chosen optimally with no adjustment costs or frictions, the input levels are perfectly dependent of each other (the "collinearity problem"). This collinearity issue may pose a problem especially for some estimators which rely on a control function approach of production function parameters 3 Lastly, some specific functional form assumptions can be more appropriate than others, due to, for example, the particular type of labor market.

Parallel to the econometric literature, two other strands of research focus on market imperfections. One is the literature on output market imperfect competition which follows the lead of the seminal papers of Hall (1986. 1988. 1991). The other strand. led by McDonald and Solow (1981), focuses on imperfections in labor markets due to unionization.

Only a few studies empirically investigate the possibility of having imperfect competition in both product and labor factor markets. Among others, Bughin (1993, 1996), Dobbelaere (2004), Galí et al. (2007), Abraham et al. (2009), Crépon et al. (2010), and Dobbelaere and Mairesse (2013) consider the possibility of imperfections in both product and factor markets, by taking into account the fact that wages are no longer exogenous.

Bughin (1993), studying the Belgian chemical industry (and four Belgian manufacturing sectors in Bughin (1996)), considers imperfections in product and factor markets, but does not provide insights about the unobserved productivity. Moreover, he does not consider possible endogeneity issues tailored to the selection bias (due to the omission of firms' entry and exit). Also in Dobbelaere (2004). Crépon et al. (2010). and in Dobbelaere and Mairesse (2013), the main focus is the heterogeneity in price-cost markup and workers' bargaining power parameters, rather than on productivity and endogeneity issues. Abraham et al. (2009), using Belgian firm-level data, simultaneously estimate price-cost margins and unions bargaining power to analyze how price setting and bargaining power are affected by globalization. Although Abraham et al. (2009) apply the Olley and Pakes (1996) method to deal with the simultaneity issue, they do not correct for the unavailability of physical output volumes, replacing the volumes of productions with deflated firm-level sales. The omission of the output price might lead to correlation between the input choices and the productivity shock, yielding biased estimated coefficients.

Next to the main contribution of assessing the impact of trade unions' power on productivity growth, this paper bridges the gap between the empirical research on production functions and the market imperfections literature. We provide a way to model how firms deal with output and labor market rigidities, and, at the same time, we address the potential endogeneity issues concerning the simultaneity, the collinearity of inputs, and the omitted output price biases. Second, we consider to what extent the estimated unobserved productivity is sensitive to the different model specifications and to the different econo-

\footnotetext{
${ }^{3}$ See Ackerberg et al. (2006). Wooldridge $(2009)$, and Gandhi et al.'s $\left.\sqrt{2011}\right)$ critique on both Olley and Pakes (1996) and Levinsohn and Petrin (2003).
} 
metric approaches to identify the structural parameters of the model. To the best of our knowledge, this particular analysis has not been done vet. A recent studv of Dobbelaere and Vancauteren (2014) relates markups and labor market imperfections to TFP. The authors add one extra labor market regime referred to as monopsony in their analysis and look in a rather descriptive way to what extent these labor market settings and markups jointly affect the distributional aspects of TFP. Third, we provide further empirical evidence of the imperfect competition on the product and labor markets using up-to-date estimation approaches.

To assess the impact of workers' bargaining power due to trade unionization on firm productivity growth, we use a firm-level dataset of 21 Dutch manufacturing sectors over the period 1989-2008. The remainder of the paper is organized as follows. In Section 2 we formulate a measure of total factor productivity (TFP) that allows for both output and labor market power. Section 3 reviews the main estimation techniques. Section 4 describes the data, and results on the relevant structural parameters are reported in Section 5. Section 6 discusses the results concerning the presence of trade unions and TFP growth rates. The conclusions are drawn in the final section.

\section{The model: Building blocks}

\subsection{The standard setting}

As in Ackerberg et al. (2007), the starting point is a Cobb-Douglas production function, where the gross output $Q_{i t}$ of firm $i$ at time $t$ relates to three specific inputs as follows:

$$
Q_{i t}=A_{i t} K_{i t}^{\theta_{i K t}} L_{i t}^{\theta_{i L t}} M_{i t}^{\theta_{i M t}}
$$

where $K_{i t}$ denotes capital, $L_{i t}$ labor, and $M_{i t}$ intermediate goods, consisting of materials and energy, interchangeably referred to as 'materials' throughout the paper. $A_{i t}$ represents the Hicksian neutral efficiency level, and is defined as Total Factor Productivity (TFP) $4 \theta_{i K t}, \theta_{i L t}, \theta_{i M t}$ are the firms' elasticities of output with respect to capital, labor, and materials, respectively. Taking natural logs of (1) results in a linear function,

$$
q_{i t}=\theta_{0}+\theta_{i K t} k_{i t}+\theta_{i L t} l_{i t}+\theta_{i M t} m_{i t}+a_{i t},
$$

where lower-case letters refer to natural logarithms. The logarithm of $A_{i t}$ is defined as $\log \left(A_{i t}\right) \equiv \theta_{0}+a_{i t}$, where $\theta_{0}$ measures the mean productivity level across firms and over time, while $a_{i t}$ is the productivity shock which is observable by the firm (for example, managerial ability, quality of research), but unobservable to the econometrician and likely to be correlated with the input factor variables, hence a source of potential endogeneity.

\footnotetext{
${ }^{4} \mathrm{MFP}$ (Multi-Factor Productivity) is sometimes used interchangeably with TFP, even if there is a slight difference between what they may include. Indeed, taking into account all the factors influencing output levels can be unrealistic, therefore MFP may be a more appropriate term to use. However, the term TFP continues to be used more widely.
} 
The time-varying, input-dependent elasticity of scale $\theta_{i t}$ is defined as the sum of all output elasticities with respect to the three nonnegative factor inputs, $X_{i k t}$ :

$$
\theta_{i t} \equiv \sum_{k \in\{K, L, M\}} \frac{\partial Q_{i t}}{\partial X_{i k t}} \frac{X_{i k t}}{Q_{i t}} \equiv \sum_{k \in\{K, L, M\}} \theta_{i k t} .
$$

\subsection{Price markup: considering the omitted output prices}

As we observe deflated gross output, input coefficients might be biased if the firm-level price variation is correlated with the input choice. To see this, we express the deflated gross output as $Y_{i t} \equiv \frac{Q_{i t}\left(P_{i t}\right) P_{i t}}{P_{t}^{j}} \exp \left(u_{i t}^{y}\right)$, where $P_{i t}$ is the firm-level price, $P_{t}^{j}$ is the price index of industry $j(\equiv j(i))$, and $u_{i t}^{y}$ represents the measurement error in $Y_{i t}$. In logs, we have:

$$
y_{i t}=q_{i t}+\left(p_{i t}-p_{t}^{j}\right)+u_{i t}^{y}
$$

Substituting equation (22) into (3), and taking $y_{i t}$ as dependent variable, the unobserved firm-level price deviations $\left(p_{i t}-p_{t}^{j}\right)$ will enter the production function as an extra error component. This will introduce potential correlation with the input choices, if $E\left(x_{i t}\left(p_{i t}-\right.\right.$ $\left.\left.p_{t}^{j}\right)\right) \neq 0$, where $x_{i t} \equiv\left(l_{i t}, k_{i t}, m_{i t}\right)^{\prime}$. possibly vielding biased input coefficients (Klette and Griliches, 1996; De Loecker, 2011). In order to estimate the production function consistently, without information on establishment-level prices, we proceed by imposing some structure on the demand system (Foster et al., 2008).

Following Klette and Griliches (1996) and De Loecker (2011), we take a standard horizontal product differentiation demand system (constant elasticity of substitution, CES), allowing for different substitution patterns by sector $j$, as we assume that consumers have an unbounded taste for variety, therefore every firm will produce a distinct variety:

$$
Q_{i t}=Q_{t}^{j}\left(P_{i t} / P_{t}^{j}\right)^{\eta_{j}} \exp \left(u_{i t}^{d}\right) \Leftrightarrow P_{i t}=P_{t}^{j}\left(Q_{i t} / Q_{t}^{j}\right)^{1 / \eta_{j}} \exp \left(-u_{i t}^{d} / \eta_{j}\right),
$$

where $Q_{t}^{j}$ is the sector $j$ production index, and $u_{i t}^{d}$ is an idiosyncratic firm-specific demand shock. , and $\eta_{j}$ is the price elasticity of demand for differentiated goods in sector $j$. Taking logarithms, we can write the right hand side of equation (4) as the inverse demand function:

$$
p_{i t}=p_{t}^{j}+\frac{1}{\eta_{j}}\left(q_{i t}-q_{t}^{j}\right)-\frac{1}{\eta_{j}} u_{i t}^{d}
$$

Taking the inverse demand function (5) into account, the log deflated output (3) can be expressed as

$$
y_{i t}=q_{i t}+\frac{1}{\eta_{j}}\left(q_{i t}-q_{t}^{j}\right)-\frac{1}{\eta_{j}} u_{i t}^{d}+u_{i t}^{y}
$$

Finally, combining equations (2) and (6), and defining the price markup as $\mu_{j} \equiv$ 
$\frac{1}{1+1 / \eta_{j}}=\eta_{j} /\left(1+\eta_{j}\right) 5$ where $\eta_{j}<-1$, the deflated gross output can be written as:

$$
y_{i t}=\gamma_{i 0 t}+\gamma_{i K t} k_{i t}+\gamma_{i M t} m_{i t}+\gamma_{i L t} l_{i t}-\frac{1}{\eta_{j}} q_{t}^{j}+\tilde{a}_{i t}+\tilde{u}_{i t}
$$

where $\gamma_{i 0 t} \equiv \theta_{0} / \mu_{j}, \gamma_{i k t} \equiv \theta_{i k t} / \mu_{j}, k=K, L, M$ are the factor input elasticities, $\tilde{a}_{i t} \equiv a_{i t} / \mu_{j}$ the productivity shock, $\tilde{u}_{i t} \equiv \tilde{u}_{i t}^{d}+\widetilde{u}_{i t}^{y}$, where $\tilde{u}_{i t}^{d} \equiv-u_{i t}^{d} / \eta$ is the demand shock and $\widetilde{u}_{i t}^{y}$ is the measurement error in $y_{i t}$.

By introducing a firm's demand system when modeling a production function, we are able to decompose the traditional measured productivity gains into real productivity gains, $a_{i t}$, an idiosyncratic firm-specific demand shock, $u_{i t}^{d}$, and a measurement error, $u_{i t}^{y}$. Moreover, as in Klette and Griliches (1996), we derive an expression for deflated revenue in an imperfectly competitive framework, where it is possible to obtain an estimate of the demand elasticity $\eta_{j}$, by simply adding industry output as an additional regressor to proxy for unobserved firm-level prices 6 The advantage of this structural approach consists in estimating the production function coefficients, controlling for price and demand variation. In this way, we get rid of the potential correlation between measured productivity and all those factors that might have an impact on prices and demand, but are not related to the true productivity (for example, in open economies, real exchange rate appreciation pulls down the output prices of the tradeable goods).

\subsection{Wage markup: union bargaining power}

In this section, we relax the conventional assumption of perfect competition in the labor market, allowing both firms and workers' unions to have some market power.

Many authors have studied the influence of market power of unions, by introducing wage rigidities through efficiency wages. For instance. Hall (1991). following McDonald and Solow (1981), assumes that the firm wages and level of employment are jointly determined according to an efficient bargaining scheme between the firm and its workers. In this case, the wage of workers is determined at a level which is higher than the firm's marginal revenue of labor. Workers in firms with some degree of market power on the output market can earn wages that are much higher than the competitive industry wage level.

The workers in the firm bargain with the firm over both the levels of employment and of the wage. In particular, the workers' objective is specified as the union's aggregate gain to the workers from membership, $U_{i t}\left(W_{i t}, L_{i t}\right) \equiv L_{i t}\left(W_{i t}-\bar{W}_{i t}\right)$, where $\bar{W}_{i t}$ is the reservation wage (i.e., the theoretical wage valid on an imperfectly competitive output market and a perfectly competitive labor market), and $W_{i t}$ is the negotiated wage 7 The standard static

\footnotetext{
${ }^{5}$ In case of perfect competition, the cross price elasticity tends to minus infinity and the output price markup goes to one.

${ }^{6}$ This model has been first proposed by Klette and Griliches (1996), but De Loecker (2011) was the first to implement a correction for output market imperfection into the semi-parametric estimation framework introduced by Olley and Pakes (1996).

${ }^{7}$ According to McDonald and Solow (1981) the workers' objective in their efficient bargaining model can
} 
firm's objective is to maximize its short-run profit, $\Pi_{i t}$, given by the difference between the total revenue and the total costs, $\Pi_{i t} \equiv P_{i t}\left(Q_{i t}\right) Q_{i t}-W_{i t} L_{i t}-R_{i t} K_{i t}-Z_{i t} M_{i t}$. We assume that there are costless adjustment frictions in both the capital and materials markets, where the capital and materials levels are held fixed for a time period, and the maximization of $\Pi_{i t}$ with respect to $K_{i t}$ and to $M_{i t}$ yields the trivial solution of marginal product of such inputs equal to zero.

The efficient bargaining model can be written as a weighted average of the logarithms of workers' aggregate gain from union membership and the firm's profit:

$$
\max _{W_{i t}, L_{i t}, K_{i t}, M_{i t}}\left[\phi_{i t} \log \left(U_{i t}\left(W_{i t}, L_{i t}\right)\right)+\left(1-\phi_{i t}\right) \log \Pi_{i t}\right]
$$

where $\phi_{i t} \in[0,1]$ is the degree of union bargaining power. The maximization of the union's objective is with respect to the negotiated wage $W_{i t}$ and labor $L_{i t}$. The firm maximizes also with respect to $W_{i t}$ and $L_{i t}$ (but also possibly with respect to capital and materials, $K_{i t}$ and $M_{i t}$, if one assumes these to be flexible).

The assumption of imperfect labor market could imply the presence of adjustment costs (Bond and Söderbom, 2005), and the adoption of a dynamic optimization framework that accounts for both costs of adjusting capital and labor (Cooper and Haltiwanger, 2006) could be appropriate. However, for reasons of analytical and computational tractability the present study focuses only on a static optimization setting.

Assuming that the number of firms in sector $j$ is so large that the aggregate demand does not vary with changes in the demand faced by firm $i$, i.e. $\frac{\partial Q_{t}^{j} / Q_{t}^{j}}{\partial Q_{i t} / Q_{i t}}=0.8$ the FOCs of this problem can be written as:

$$
\begin{aligned}
\text { w.r.t. } \quad L_{i t} & \rightarrow\left(1-\phi_{i t}\right) \frac{W_{i t}-\left(1+\frac{1}{\eta_{j}}\right) P_{i t}\left(Q_{i t}\right) \frac{\partial Q_{i t}}{\partial L_{i t}}}{\Pi_{i t}}=\frac{\phi_{i t}}{L_{i t}}, \\
\text { w.r.t. } \quad W_{i t} & \rightarrow\left(1-\phi_{i t}\right) \frac{W_{i t}-\bar{W}_{i t}}{\Pi_{i t}}=\frac{\phi_{i t}}{L_{i t}} .
\end{aligned}
$$

From (8) it follows that, when $\phi_{i t}=0$, the marginal revenue product of labor is equal to the wage rate. However, in general, with $\phi_{i t} \in(0,1)$, by rewriting equation (9), we can express the bargained wage rate as a function of the bargaining parameter, $\phi_{i t}$, and the

be specified in two alternative ways: either as the union's aggregate gain to the workers from membership, or taking account of the unemployment benefits, as $L_{i t} W_{i t}+\bar{W}_{i t}\left(N_{i t}-L_{i t}\right)$, where $N_{i t}$ is the labor supply. McDonald and Solow (1981) judge the first specification as the most appropriate one for real life. In fact, in the second specification, if $\bar{W}_{i t}$ falls, the firm would have to increase its wage offer to make up for a reduction in $\bar{W}_{i t}$, to keep the level of union utility unchanged. Hence, we advocate McDonald and Solow's (1981) suggestion and take the union preferences $U_{i t}\left(W_{i t}, L_{i t}\right) \equiv L_{i t}\left(W_{i t}-\bar{W}_{i t}\right)$ as a function of both wages and employment.

${ }^{8}$ The maximization of profits with respect to labor yields the following expression $\left[1+\frac{1}{\eta_{j}}\left(1-\frac{\partial Q_{t}^{j}}{\partial Q_{i t}} \frac{Q_{i t}}{Q_{t}^{j}}\right)\right] P_{i t}\left(Q_{i t}\right) \frac{\partial Q_{i t}}{\partial L_{i t}}-W_{i t}$, where the term $\frac{\partial Q_{t}^{j}}{\partial Q_{i t}} \frac{Q_{i t}}{Q_{t}^{j}}$ represents the firms' conjectural variation, that is the strategic response of firm $i$ to the quantities chosen by the other firms, assuming a Cournot oligopolistic model, where there are few firms in each sector $j$. 
ratio between profits and cost of labor:

$$
\frac{W_{i t}-\bar{W}_{i t}}{W_{i t}}=\frac{\phi_{i t}}{1-\phi_{i t}} \frac{\Pi_{i t}}{L_{i t} W_{i t}} .
$$

Defining $\mu_{i t}^{W} \equiv \frac{W_{i t}-\bar{W}_{i t}}{W_{i t}}$ as the wage markup, one can see how this is directly depending on the union's bargaining power. Equation (10) summarizes the features of the efficient bargaining model. The wage wedge $W_{i t}-\bar{W}_{i t}$ is increasing with the bargaining power $\phi_{i t}$ and with firm performance, measured as profit per employee $\Pi_{i t} / L_{i t}$. The profit per employee is a good measure of firm performance, as it proxies for earnings on intangible assets, such as knowledge, reputation, and collaboration created by talented workers (Bryan, 2007).

Combining equations (8) and (9), we can write the marginal revenue product of labor as

$$
\left(\frac{\eta_{j}+1}{\eta_{j}}\right) P_{i t}\left(Q_{i t}\right) \frac{\partial Q_{i t}}{\partial L_{i t}}=\bar{W}_{i t}
$$

Therefore, by multiplying both sides of (11) by $\frac{L_{i t}}{Q_{i t}}$, and using the definitions of $\theta_{i L t}$ and $\mu_{j}$, we can derive

$$
\gamma_{i L t} \equiv \theta_{i L t} / \mu_{j}=\frac{\bar{W}_{i t} L_{i t}}{P_{i t}\left(Q_{i t}\right) Q_{i t}}=\frac{\bar{W}_{i t}}{W_{i t}} \frac{W_{i t} L_{i t}}{P_{i t}\left(Q_{i t}\right) Q_{i t}} \equiv \frac{\bar{W}_{i t}}{W_{i t}} \times s_{i L t},
$$

with $s_{i L t}$ the labor share in total production. Thus, under imperfect competition in both output and labor markets, the labor elasticity is a function of the labor share and the wage markup:

$$
\gamma_{i L t}=s_{i L t}\left(1-\mu_{i t}^{W}\right)
$$

At this stage, it is intuitively clear how the exclusion of frictions in the labor market (i.e., $\phi_{i t}=0$ or $W_{i t}=\bar{W}_{i t}$ ) might lead to misestimating the firm's market power. When there is no imperfect competition in the labor market, firms set the wage at the lowest value possible, ultimately equal to the competitive wage, i.e., $W_{i t}=\bar{W}_{i t}$ (and, therefore, $\left.\mu_{i t}^{W}=0\right)$. For $W_{i t}$ that tends to $\bar{W}_{i t}$, the wage markup decreases, given that the elasticity and the share of labor are constant, which is inversely related to the output markup $\mu_{j}$.

This apparently direct positive relationship between the wage and the product price markup could be interpreted as if the larger the firm's rent, the larger the wage markup (as in Dobbelaere, 2004). However, according to our analysis, it might be just an underestimation of the true level of price-cost margins that is caused by the omission of direct effects of the wage bill on marginal costs (Bughin, 1993). As a matter of fact, finding a significant estimate for the wage markup parameter $\mu_{i t}^{W}$ means that the workers' union has a degree of bargaining power, $\phi_{i t}$, which erodes the existing monopoly rents. Therefore, we expect price-cost margins and bargaining power parameters (both wage markup and bargaining elasticity) to be negatively related. 
Finally, we include the labor elasticity, as expressed in (12), in the deflated revenue function (77). The resulting estimating equation assuming labor market frictions can be expressed as 9

$$
\begin{aligned}
& \text { a. } y_{i t}=\gamma_{i 0 t}+\gamma_{i K t} k_{i t}+\gamma_{i M t} m_{i t}+\left(1-\mu_{i t}^{W}\right) s_{i L t} l_{i t}-\frac{1}{\eta_{j}} q_{t}^{j}+\tilde{a}_{i t}+\tilde{u}_{i t}, \\
& \text { b. } \quad y_{i t}=\gamma_{i 0 t}+\gamma_{i K t} k_{i t}+\gamma_{i M t} m_{i t}+\gamma_{i L t} l_{i t}-\frac{1}{\eta_{j}} q_{t}^{j}+\tilde{a}_{i t}+\tilde{u}_{i t}, \\
& \text { c. } \quad q_{i t}=\theta_{i 0 t}+\theta_{i K t} k_{i t}+\theta_{i M t} m_{i t}+\theta_{i L t} l_{i t}+a_{i t}+u_{i t}^{y} .
\end{aligned}
$$

Estimating equation $b$ in (14) represents the deflated revenue function allowing for imperfect competition in the product market and perfect competition in the labor market. Specification $b$ could still represent the revenue function of a firm producing in a unionized labor market where the workers bargain only over the wage and let the employers determine the level of the employment, i.e., right-to-manage (Dobbelaere and Mairesse, 2013). Specification $c$ in (15) represents the production function in the perfect competition case, and it is used as benchmark.

Estimation of equation (13) can be done following several estimation approaches, under appropriate corresponding distributional assumptions, which will be discussed in the next section.

\section{Estimation and identification strategies}

In this section we briefly review the main problems concerning the estimation of a production function. Moreover, we discuss the advantages and drawbacks of some widely adopted estimation techniques, linking them to our structural framework of imperfect competition. The literature that we are going to investigate does not necessarily discuss our specification (13), but typically the version without imperfect competition in both output and labor markets, i.e., with $\mu_{i t}^{W}=1$ and $1 / \eta_{j}=0$. The corresponding equation is given by

$$
y_{i t}=\gamma_{i 0 t}+\gamma_{i K t} k_{i t}+\gamma_{i M t} m_{i t}+\gamma_{i L t} l_{i t}+a_{i t}+u_{i t} .
$$

\footnotetext{
${ }^{9}$ This functional form allows us to directly obtain an estimate of $\mu_{i t}^{W}$ and $c$, along with the estimation of the other regression parameters. As a robustness check, we also specify the labor elasticity in the empirical application as $\gamma_{i L t}=s_{i L t}-\frac{\phi_{i t}}{1-\phi_{i t}} \frac{\Pi_{i t}}{P_{i t}\left(Q_{i t}\right) Q_{i t}}$, and directly obtain an estimate of $\frac{\phi_{i t}}{1-\phi_{i t}}$ from the following estimating equation:$$
y_{i t}-s_{i L t} l_{i t}=\gamma_{i 0 t}+\gamma_{i K t} k_{i t}+\gamma_{i M t} m_{i t}-\frac{\phi_{i t}}{1-\phi_{i t}} \frac{\Pi_{i t}}{P_{i t}\left(Q_{i t}\right) Q_{i t}} l_{i t}-\frac{1}{\eta_{j}} q_{t}^{j}+\tilde{a}_{i t}+\tilde{u}_{i t} .
$$

The bargaining parameter, $\phi_{i t}$, in the first specification, and the wage markup, $\mu_{i t}^{W}$, in the latter, are retrieved by exploiting the functional relation of equation (10), where:$$
\frac{W_{i t}-\bar{W}_{i t}}{W_{i t}}=\hat{\mu}_{i t}^{W}=\frac{\hat{\phi}_{i t}}{1-\hat{\phi}_{i t}} \frac{\Pi_{i t}}{W_{i t} L_{i t}}
$$

and standard errors are computed using the delta method. This yields similar empirical results. 
In empirical applications one usually assumes that the parameters are constant, i.e., $\gamma_{i k t}=$ $\gamma_{k}$, for $k \in\{0, K, L, M\}$, while $u_{i t}$ is treated as a usual error term. The problem is the potential correlation between $a_{i t}$ and the inputs that are chosen at time $t$, in our case at least $l_{i t}$. Assuming that the unobserved productivity is constant over time $\left(a_{i t}=a_{i}\right)$, the potential endogeneity between $a_{i}$ and the inputs is controlled by exploiting the panel structure of the data, for instance, by using the fixed-effects estimator. However, if we believe that $a_{i}$ evolves over time instead, using the fixed effects estimator does not solve the endogeneity problem, and alternatives have to be investigated.

One natural alternative is the use of an instrumental variables (IV) estimator, if instruments can be found that are correlated with the inputs, but uncorrelated with $a_{i t}$ and $u_{i t}$. A natural candidate for such instruments are the input prices. However, as discussed

by Ackerberg et al. (2007), using input prices as instruments has not been uniformly successful in practice. Moreover, assuming market frictions in the input markets (as we do with respect to the labor market), might imply correlation between $a_{i}$ and the input prices (in our case wages). Therefore, other instruments, or other estimation approaches have to be investigated.

\subsection{Control function estimation approach}

In their seminal paper, Olley and Pakes (1996) propose a control function approach to estimate production functions (which they considered without intermediate goods, and where labor is the only endogenous input). In particular, Ollev and Pakes (1996) assume that the investment level is strictly monotonic in the scalar unobservable productivity level $a_{i t}$. More precisely, they assume that investment $i_{i t}$ satisfies $i_{i t}=j_{t}\left(a_{i t}, k_{i t}\right)$, strictly increasing in $a_{i t}$. It is then possible to invert the investment demand function. This yields a so-called control function, expressing productivity as a function of investment, along with other variables (in their case capital $\left.k_{i t}\right): a_{i t}=j_{t}^{-1}\left(i_{i t}, k_{i t}\right)$. By substituting out the unobserved productivity $a_{i t}$ using this control function, the resulting equation does not have endogeneity problems anymore.

However, when inverting the investment function, to guarantee the one-to-one mapping between firm-level productivity and the observable investment, the investment variable has to be strictly positive. As investments in the data are often zero, Levinsohn and Petrin (2003) also include intermediate goods as extra endogenous input in the production function. Then they propose the use of an intermediate input demand function, such as materials and energy demand functions, as a proxy for unobserved productivity: $m_{i t}=f_{t}\left(a_{i t}, k_{i t}\right)$. This yields an alternative control function, assuming that $f_{t}$ is strictly increasing in $m_{i t}: a_{i t}=f_{t}^{-1}\left(m_{i t}, k_{i t}\right)$.

In practice, the estimation approach suggested by Ollev and Pakes (1996), and later by Levinsohn and Petrin (2003), is composed of two stages. In the first stage, one estimates the labor elasticity, along with the substituted replacement function, which can be approximated by a sufficiently high order polynomial in its arguments. However, due to the nonparametric character of the control function the capital and possibly materials 
elasticities cannot be estimated in the first stage. Thus, in the first stage, focusing on the Levinsohn and Petrin (2003) approach, one runs a regression

$$
y_{i t}=\gamma_{L} l_{i t}+\phi_{t}\left(m_{i t}, k_{i t}\right)+u_{i t},
$$

with $\phi_{t}$ approximated by a higher order polynomial in $m_{i t}$ and $k_{i t}$, where $\phi_{t}$ satisfies

$$
\phi_{t}\left(m_{i t}, k_{i t}\right)=\gamma_{K} k_{i t}+\gamma_{M} m_{i t}+f_{t}^{-1}\left(m_{i t}, k_{i t}\right) .
$$

In the second stage, to identify the other production function parameters (capital and intermediate goods), Olley and Pakes (1996) assume that the technological progress, $a_{i t}$, depends on the information known by the firm $i$ at time $t-1$ (information set $I_{i t-1}$ ). Under the additional assumption that $a_{i t}$ follows a first-order Markov process, the past realizations of $a_{i t}$ constitute the information set. In other words,

$$
a_{i t}=h\left(I_{i t-1}\right)+\xi_{i t}=h\left(a_{i t-1}\right)+\xi_{i t},
$$

where $\xi_{i t}$ represents the unanticipated innovative shock to productivity, assumed to be uncorrelated with materials and capital in period $t-1$. Using the first stage estimates from (17) and assumption (18), we can write the production function (16) as:

$$
y_{i t}-\widehat{\gamma}_{L} l_{i t}=\gamma_{0}+\gamma_{K} k_{i t}+\gamma_{M} m_{i t}+h\left[\widehat{\phi}_{i t-1}-\gamma_{0}-\gamma_{K} k_{i t-1}-\gamma_{M} m_{i t-1}\right]+\xi_{i t}+u_{i t},
$$

where

$$
\widehat{\phi}_{i t-1}=\widehat{\phi}_{t}\left(m_{i t-1}, k_{i t-1}\right) \text {. }
$$

Approximating $h(\cdot)$ with a flexible polynomial, (19) can be estimated, using lagged materials $m_{i t-1}$ as instrument for materials $m_{i t}$, since $m_{i t}$ might be correlated with $\xi_{i t}$.

A restricting assumption of the Olley and Pakes (1996) model concerns the timing and dynamic nature of inputs, i.e., some inputs are more "dynamic in nature" than others. In particular, when selecting the state variables that enter the firm's expected discounted profit maximization, Olley and Pakes (1996) define capital as a dynamic input, i.e., its choice of the current period affects the choice of the next period. Labor (and in case of Levinsohn and Petrin, 2003 also materials), on the other hand, is assumed to be a more flexible and non-dynamic input, therefore, it is implicitly assumed that there are no labor (and materials) adjustment costs.

\subsection{Ackerberg et al. (2006) critique and solutions}

According to Ackerberg et al. (2006), an important drawback of the Ollev and Pakes (1996) (and Levinsohn and Petrin, 2003) approach in the context of (16) arises form collinearity between labor and the polynomial in materials (or investment) and capital. As a matter of fact, in the first stage, the labor coefficient could be unidentified, if the regressor $l_{i t}$ does 
not have any sample variability that is independent of the other regressors. To see this, let us consider the approach of Levinsohn and Petrin (2003) which assumes that $m_{i t}$ and $l_{i t}$ are perfectly flexible inputs, chosen simultaneously. In the context of equation (16), i.e., under perfect competition and with $k_{i t}$ an inflexible factor input, the firm's state variables at time $t$ are given by $a_{i t}, k_{i t}, P_{t}, W_{t}$, and $Z_{t}$, where the output price $P_{t}$, wage $W_{t}$, an the materials price $Z_{t}$ are assumed to be constant over firms (assuming perfect competition in the three markets). The demand of materials and labor are then functions of these state variables, i.e., $m_{i t}=f\left(a_{i t}, k_{i t}, P_{t}, W_{t}, Z_{t}\right) \equiv f_{t}\left(a_{i t}, k_{i t}\right)$, and $l_{i t}=q\left(a_{i t}, k_{i t}, P_{t}, W_{t}, Z_{t}\right) \equiv$ $q_{t}\left(a_{i t}, k_{i t}\right)$. Therefore, they both depend on the same state variables, $a_{i t}$ and $k_{i t}$, and $l_{i t}=q_{t}\left(f_{t}^{-1}\left(m_{i t}, k_{i t}\right), k_{i t}\right)=s_{t}\left(m_{i t}, k_{i t}\right)$, leaving the labor input as a time-varying function of materials and capital. But then there is no independent firm-level source of variation that could help identify the labor elasticity coefficient in the first stage. In addition, Ackerberg et al. (2006) show that these problems remain intact, even if one is able to derive $f_{t}^{-1}$ explicitly, assuming a Cobb-Douglas production function: again, one cannot identify the labor elasticity coefficient in the first stage.

Ackerberg et al. (2006) discuss two possible ways to break this collinearity issue. One way is to assume that the firm makes optimization errors only in the choice of labor (optimization error in materials adds an additional unobservable, violating the scalar unobservability assumption, needed to construct a control function). This error does not enter the production function and will move $l_{i t}$ around independently of the control function.

The second option is to make specific timing assumptions that would justify the independency of cross-sectional variation of $l_{i t}$, conditional on the choices of materials and capital. In particular, Ackerberg et al. (2006) propose to assume that, next to capital, also labor is a state variable, i.e., not fully flexible, and that labor is chosen somewhere after the choice of capital (at time $t-1$ ) and before the choice of materials (at time $t$ ). Given this timing assumption, Ackerberg et al. (2006) proceed with a two-step estimation approach, where the labor coefficient is identified only in the second stage, together with the capital coefficients. As estimation approach, Ackerberg et al. (2006) propose to use two equations, namely, first

$$
y_{i t}=\gamma_{K} k_{i t}+\gamma_{M} m_{i t}+\gamma_{L} l_{i t}+g\left(l_{i t}, m_{i t}, k_{i t}\right)+u_{i t},
$$

with $g$ a polynomial in terms of $l_{i t}, m_{i t}$, and $k_{i t}$, and assuming that the expectation of $u_{i t}$ conditional on time $t$ information is equal to zero. The second equation follows from (18), and is given by

$$
g\left(l_{i t}, m_{i t}, k_{i t}\right)=h\left[g\left(l_{i t-1}, m_{i t-1}, k_{i t-1}\right)\right]+\xi_{i t},
$$

with $h$ a univariate polynomial, and assuming that the expectation of $\xi_{i t}$ conditional on time $t-1$ information is equal to zero. This approach is based on Wooldridge (2009) in order to obtain efficient GMM estimates and standard errors in one step. In fact, 
Wooldridge (2009) uses the second equation substituted in the first one, yielding

$$
y_{i t}=\gamma_{K} k_{i t}+\gamma_{M} m_{i t}+\gamma_{L} l_{i t}+h\left[g\left(l_{i t-1}, m_{i t-1}, k_{i t-1}\right)\right]+\xi_{i t}+u_{i t}
$$

together with the assumption that the expectation of $\xi_{i t}+u_{i t}$ conditional on time $t-1$ information is equal to zero.

\subsection{Bond and Söderbom (2005) critique and IV solution}

Bond and Söderbom (2005) also illustrate the identification issues concerning the parameters of a Cobb-Douglas production function, when these are assumed to be perfectly flexible. Indeed, when the input prices are common to all firms and inputs are chosen optimally with no adjustment frictions, assuming perfect competition on output and input markets, the levels of the inputs are perfectly collinear (in the sense of linear regression) with each other and the productivity. Bond and Söderbom (2005) show how this collinearity problem is not solved by assuming that one of the inputs, i.e., the level of capital, is predetermined (chosen in the previous period). According to these authors, the only assumption that guarantees the identification of the structural parameters is a positive and exogenous variation in input prices (e.g. deriving from adjustment costs). However, according to Bond and Söderbom (2005), the presence of unobserved variation across firms in prices might rule out the control function approach, which is assumed to be common to all firms.

To break the collinearity issue, Bond and Söderbom (2005) consider the dynamic problem of a firm maximizing the current and future profits in the presence of firm-specific adjustment costs and productivity shocks. Simulating data for a two-factor Cobb-Douglas production function, Bond and Söderbom (2005) show that the production function coefficients are identified provided that there are adjustment costs for each input and that these inputs are subject to different levels of adjustment costs. Given the empirical evidence of the presence of such adjustment costs presence, Bond and Söderbom (2005) suggest the use of instrumental variables methods to consistently estimate the parameters of the production function. In particular, the lagged level of inputs constitute informative instruments, as the presence of cost frictions makes the variation of these inputs persistent.

\subsection{Gandhi et al. (2011) critique and solution}

As later stressed by Gandhi et al. (2011), if one is not willing to assume the presence of adjustment frictions in all inputs, the nonparametric identification of the production function fails in the presence of flexible inputs. In particular, Gandhi et al. (2011) show how, in the perfect competition case, when materials are assumed to be a flexible input, its elasticity suffers from an identification problem emerging from the fact that there is no source of cross-sectional variation in $m_{i t}$ independent of the firm's remaining productive inputs $\left(l_{i t}, k_{i t}, a_{i t}\right)$. Moreover, according to Gandhi et al. (2011) the collinearity problem described by Ackerberg et al. (2006) is not solved. To argue this, they consider equation 
(23) of the Wooldridge (2009) approach, together with the (specialized) moment condition

$$
E\left(\xi_{i t}+u_{i t} \mid l_{i t-1}, m_{i t-1}, k_{i t-1}\right)=0 .
$$

The lagged value $m_{i t-1}$ is intended to act as an instrument for the endogenous $m_{i t}$. However, $m_{i t-1}$ alone cannot act as an excluded variable and be a valid instrument for $m_{i t}$, since $m_{i t-1}$ is already included in (23) as an additional regressor, and, moreover, it is fully collinear with $l_{i t-1}$ and $k_{i t-1}$.

Gandhi et al. (2011) propose a solution that identifies the coefficient of a flexible input and is based on a transformation of the firm's first order condition for flexible inputs, i.e. for materials. The key idea behind their approach is to combine the transformation of the FOC for materials with the idea of measurement error in output (unanticipated productivity shock). In particular, they obtain a simple "share regression" model, $\log \left(s_{i M t}\right)=\log \left(\theta_{M}\right)-u_{i t}^{q}$, and perform nonparametric regression of $\log \left(s_{i M t}\right)$ on all inputs (since $\log \left(\theta_{M}\right)$ depends on all productive inputs). Since the ex-post shock, $u_{i t}^{q}$, is assumed to be independent of the three inputs, the non-parametric share regression identifies both material elasticity and $u_{i t}^{q}$.

\subsection{Estimation using market imperfections}

In this subsection we describe and motivate our three estimation approaches, also referring to the discussion in the previous subsections. Our starting point is equation (13), assuming that the structural parameters are drawn from probability distributions that do not vary over firms or time, i.e., the resulting estimation equation is

$$
y_{i t}=\gamma_{0}+\gamma_{K} k_{i t}+\gamma_{M} m_{i t}+\left(1-\mu^{W}\right) s_{i L t} l_{i t}-\frac{1}{\eta_{j}} q_{t}^{j}+\tilde{a}_{i t}+\tilde{u}_{i t} .
$$

In our specification, at least, $l_{i t}$ is fully flexible. According to Bond and Söderbom (2005) this might result in perfect collinearity in a Cobb-Douglas production framework under perfect competition in output and input markets. However, due to the imposed market imperfections, we do not have this collinearity problem. First, as independent variable we do not have $l_{i t}$ in equation (24), but $s_{i L t} l_{i t}$. Second, $l_{i t}$ has to satisfy (8)-(9), avoiding that $l_{\underline{i t}}$ depends in a linear way on $\widetilde{a}_{i t}$ and the other inputs, as derived by Bond and Söderbom (2005) in the perfect competition case. Moreover, if $k_{i t}, m_{i t}$, or both are fully flexible as well, then (8)-(9) will again avoid perfect collinearity.

Next, we describe our estimation approaches, in combination with the corresponding additional distributional assumptions. As first estimation approach, we shall use the fixed effects (or within) estimator, which requires as additional assumption that $\tilde{a}_{i t}$ is not time dependent, i.e., $\tilde{a}_{i t}=\tilde{a}_{i}$.

As second estimator, we shall use the Wooldridge's (2009) estimator related to the Levinsohn and Petrin (2003) control function approach. In this case we add (18), together with the assumption that $\xi_{i t}$ has mean zero, conditional on all time $t-1$ information. To 
be able to apply the control function approach, we "derive" $\widetilde{a}_{i t}$ as a (nonlinear) function of the inputs $l_{i t}, k_{i t}$, and $m_{i t}$, and the state variables, using our set-up. When doing this, the collinearity problems described by Ackerberg et al. (2006) for the Cobb-Douglas production function do not show up, due to the market imperfections. Moreover, the assumption that the production function is a Cobb-Douglas production function avoids the nonparametric identification problems raised by Gandhi et al. (2011). However, we have to assume that $\widetilde{a}_{i t}$ is only a (nonlinear) function of the inputs $l_{i t}, k_{i t}$, and $m_{i t}$, constant over firms and time. We then use (23), updated to our specification, i.e.,

$$
y_{i t}=\gamma_{K} k_{i t}+\gamma_{M} m_{i t}+\left(1-\mu^{W}\right) s_{i L t} l_{i t}-\frac{1}{\eta_{j}} q_{t}^{j}+h\left[g\left(l_{i t-1}, m_{i t-1}, k_{i t-1}\right)\right]+\xi_{i t}+\tilde{\tilde{u}}_{i t},
$$

together with the distributional assumption that $\xi_{i t}+\tilde{\tilde{u}}_{i t}$ has mean zero, conditional on all information at time $t-1$. We estimate (25), with $g$ and $h$ specified as third order polynomials, and using as instruments the lagged inputs $l_{i t-1}, k_{i t-1}, m_{i t-1}$, and their higher order and interaction terms, up to the third order. This choice of instruments in particular makes sense if there is some persistence over time in the inputs, for instance, via $k_{i t}$. Given persistence in $k_{i t}$, there will also be persistence in the other inputs, due to the (nonlinear) dependence between the inputs.

As third estimation approach, we shall use the IV estimator. Here, we use (24), and make the assumption that $\tilde{a}_{i t}+\tilde{u}_{i t}$ has mean zero, conditional on all information available at time $t-1$. We estimate (24), using GMM, with as instruments the first and second order lags of $l_{i t}, k_{i t}$, and $m_{i t}$. Again, given persistence in, for instance, $k_{i t}$, there will also be persistence in the other inputs, making that the lagged inputs are correlated with the current inputs. However, although the IV approach has the advantage that it does not require the assumption of a control function, constant over firms and time, the cost of adopting this estimation approach is that one does not allow for the possibility that the unobserved productivity could be correlated with past choices of inputs.

\section{Data}

We extract data from Statistics Netherlands for the years 1989-2008. As an output measure, we use the deflated value of gross output $Y_{i t}\left(\equiv \frac{Q_{i t} P_{i t}}{P_{t}^{j}}\right)$ of each firm $i$ in sector $j$ in period $t$. Labor $\left(L_{i t}\right)$ refers to the number of employees in each firm for each year 10 collected in September of that year. The corresponding wages $W_{i t}$ include gross wages plus salaries and social contributions before taxes. The costs of intermediate inputs $\left(Z_{i t} M_{i t}\right)$ include costs of energy, intermediate materials, and services. The unit user costs $R_{i t}$ (of capital stock $K_{i t}$ ) are calculated as the sum of the depreciation of fixed assets and the interest charges.

The nominal gross output and intermediate inputs are deflated with the appropriate

\footnotetext{
${ }^{10}$ For each enterprise, jobs are added and adjusted for part-time and duration factors, resulting in the number of man/years expressed as Full Time Equivalents (FTEs)(Source: Statistics Netherlands)
} 
Table 4.1: Descriptive Statistics

\begin{tabular}{lrrr}
\hline variable & mean & sd & median \\
\hline$P_{i t} Q_{i t}$ & $30,438.92(\mathrm{~K} €)$ & 206823.63 & $6,830.00$ \\
$Y_{i t}$ & $26,531.56$ & 136477.83 & $6,360.17$ \\
$Z_{i t} M_{i t}$ & $21,840.75(\mathrm{~K} €)$ & 176028.74 & $4,207.00$ \\
$M_{i t}$ & $18,100.77$ & $98,131.26$ & $3,885.73$ \\
$R_{i t} K_{i t}$ & $1,566.48(\mathrm{~K} €)$ & $17,288.03$ & 227.99 \\
$K_{i t}$ & $1,671.48$ & $16,171.45$ & 247.56 \\
$L_{i t}$ & 112.16 & 303.62 & 50.00 \\
$W_{i t} L_{i t}$ & $4,575.57(\mathrm{~K} €)$ & $15,055.52$ & $1,666.00$ \\
$q_{t}^{j}$ & 0.94 & 0.15 & 0.97 \\
$s_{i L t}$ & 0.27 & 0.13 & 0.26 \\
$s_{i M t}$ & 0.62 & 0.15 & 0.62 \\
$s_{i K t}$ & 0.04 & 0.04 & 0.03 \\
$y_{i t}$ & 8.90 & 1.40 & 8.76 \\
$k_{i t}$ & 5.56 & 1.71 & 5.52 \\
$m_{i t}$ & 8.36 & 1.53 & 8.27 \\
$l_{i t}$ & 4.05 & 1.06 & 3.93 \\
\hline
\end{tabular}

Note: Averages, standard deviations, and medians are reported for all the variables included in the estimations. Source: own calculations based on data from Production Survey - Statistics Netherlands.

price indices from the input-output tables available at the NACE rev. 1 two-digits sector classification 11 For capital, we use a two-digit NACE deflator of fixed tangible assets calculated by Statistics Netherlands.

The data extracted from the Production Survey (PS) constitutes an unbalanced panel dataset of 6727 firms (with a minimum of 2001 firms in 2001 and a maximum of 5607 enterprises in 2006 and 1997) with 65866 observations spanning over 20 years and over 21 sectors. We exclude from the sample firms producing for less than two consecutive years 12 Also, firms with missing data on one of the variables used in the empirical analysis are omitted. We exclude firms exhibiting input growth rates of more than 200 percent or less than -50 percent (3822 observations dropped). We also exclude firms with an output growth of more than 300 percent or less than -90 percent (1372 observations). The resulting sample consists of 60672 observations (6718 firms).

Throughout our sample period, the PS surveys included some changes in their population designs resulting in an unbalanced panel. As a result, we cannot distinguish whether the entry or exit rates of firms resulted from survey response behavior or real economic structural behavior. The number of firms $(N)$ for each NACE rev. 1 industry is calculated by Statistics Netherlands. Table 8.4 in the Section 8 reports the sectors that were chosen with a corresponding NACE two-digit code and the corresponding number of firms.

\footnotetext{
${ }^{11}$ NACE Rev. 1 is a two-digit activity classification which was drawn up in 1989. It is a revision of the General Industrial Classification of Economic Activities within the European Community, known by the acronym NACE and originally published by Eurostat in 1970.

${ }^{12}$ The numbers of firms for each number of observations are: 700(2), 1806(3), 2556(4), 3400(5), 2760(6), 3073(7), 2256(8), 3222(9), 2730(10), 3168(11), 3396(12), 4134(13), 4032(14), 3810(15), 3856(16), 3995(17), 4806(18), 3515(19), 3520(20), where the number of observations per firm is reported between brackets.
} 
Table 4.1 reports the means, standard deviations and medians of the included data for our main variables. In particular, a summary of the of deflated revenues and inputs (in thousand Euros), along with input shares in revenue, is presented. The input shares are constructed by dividing the (undeflated) firm input costs by the corresponding firm undeflated revenue. As one can see, the dispersion of the deflated output and inputs is considerably large 13

During 1989-2008, the capital input constitutes 4.5 percent of gross output on average. The mean share of labor is 27 percent, and intermediate inputs constitute more than half of gross output (61.5 percent). Moreover, the relative dispersion of all these variables is large, especially for the share of capital. The exit rate, not reported here, is quite small (2.7 percent) and 75 percent of the firms have been active in the market for 3 to 10 years.

\section{Empirical results for the complete sample of Dutch firms}

In this section we present results for the entire manufacturing industry over the period 1989-2008, without looking at the potential heterogeneity in the structural parameters across firms and/or through time, using the random coefficients framework. Section 5.1 explores the empirical results where the relevant parameters are allowed to differ among product segments. Table 5.1 reports the estimated parameters of interest of the production function for the whole manufacturing industry. The table is organized per estimation approach: fixed effects (Within), instrumental variables (IV), Wooldridge's (2009) estimations of the Levinsohn and Petrin (2003) model (Wool.-LP). As already reported, we estimate the latter model parametrically, proxying the unknown functions $g_{t}(\cdot)$ and $h(\cdot)$ in equation (25) with polynomials of third order. To avoid further collinearity issues, the independent variable $s_{i L t} l_{i t}$ is calculated by taking for the labor the sector-specific labor production share $s_{L t}^{j}$, with $j=j_{i}$ multiplied by the logarithm of number of employees. For each econometric approach, we consider three model specifications: $a$ (the production function featuring both labor and product market imperfect competition), $b$ (product market imperfect competition only), and $c$ (no corrections for omitted price bias and labor imperfect competition). The model specifications $b$ and $c$ are included for comparison purposes only.

With every estimation technique, the results confirm the hypothesis of simultaneous output and labor markets imperfections. Columns a report evidence of markups larger than one, rent-sharing parameters and wage markups larger than zero. In line with Bughin (1993. 1996). Dobbelaere (2004). Abraham et al. (2009). and Dobbelaere and Mairesse (2013), we find that excluding the rent-sharing parameter (columns $b$ ) leads to an underestimation of the product markup. The omitted output price bias (arising from the use of deflated gross output instead of output in volumes) is evident when comparing columns $b$ and $c$. All input elasticities are biased downwards when we do not implement the correction for the omitted output price bias (as suggested by Klette and Griliches, 1996

\footnotetext{
${ }^{13}$ Averages over time and standard deviations for each sector are reported in Table 8.4 in Section 8
} 
Table 5.1: Results for the whole manufacturing industry

\begin{tabular}{|c|c|c|c|c|c|c|c|c|c|}
\hline \multirow[b]{3}{*}{$\hat{\theta}_{L}$} & \multicolumn{3}{|c|}{ Within } & \multicolumn{3}{|c|}{ IV } & \multicolumn{3}{|c|}{ Wool.-LP } \\
\hline & $a$ & $b$ & $c$ & $a$ & $b$ & $c$ & $a$ & $b$ & $c$ \\
\hline & $\begin{array}{l}0.118 \\
(0.002\end{array}$ & $\begin{array}{l}0.240 \\
(0.003)\end{array}$ & $\begin{array}{l}0.216 \\
(0.002)\end{array}$ & $\begin{array}{l}0.271 \\
(0.011)\end{array}$ & $\begin{array}{l}0.237 \\
(0.011)\end{array}$ & $\begin{array}{l}0.213 \\
(0.006)\end{array}$ & $\begin{array}{l}0.258 \\
(0.010)\end{array}$ & $\begin{array}{l}0.225 \\
(0.007)\end{array}$ & $\begin{array}{l}0.201 \\
(0.006)\end{array}$ \\
\hline$\hat{\theta}_{M}$ & $\begin{array}{l}0.864 \\
(0.006)\end{array}$ & $\begin{array}{l}0.760 \\
(0.005)\end{array}$ & $\begin{array}{l}0.680 \\
(0.001)\end{array}$ & $\begin{array}{l}0.951 \\
(0.024)\end{array}$ & $\begin{array}{l}0.811 \\
(0.012)\end{array}$ & $\begin{array}{l}0.732 \\
(0.004)\end{array}$ & $\begin{array}{l}0.912 \\
(0.021)\end{array}$ & $\begin{array}{l}0.781 \\
(0.011)\end{array}$ & $\begin{array}{l}0.716 \\
(0.004)\end{array}$ \\
\hline$\hat{\theta}_{K}$ & $\begin{array}{l}0.048 \\
(0.001)\end{array}$ & $\begin{array}{l}0.036 \\
(0.001)\end{array}$ & $\begin{array}{l}0.032 \\
(0.001)\end{array}$ & $\begin{array}{l}0.080 \\
(0.004)\end{array}$ & $\begin{array}{l}0.068 \\
(0.003)\end{array}$ & $\begin{array}{l}0.061 \\
(0.003)\end{array}$ & $\begin{array}{l}0.062 \\
(0.004)\end{array}$ & $\begin{array}{l}0.056 \\
(0.003)\end{array}$ & $\begin{array}{l}0.051 \\
(0.003)\end{array}$ \\
\hline$\hat{\theta}$ & $\begin{array}{l}1.031 \\
(0.008)\end{array}$ & $\begin{array}{l}1.036 \\
(0.007)\end{array}$ & $\begin{array}{l}0.929 \\
(0.002)\end{array}$ & $\begin{array}{l}1.301 \\
(0.034)\end{array}$ & $\begin{array}{l}1.116 \\
(0.016)\end{array}$ & $\begin{array}{l}1.006 \\
(0.002)\end{array}$ & $\begin{array}{l}1.233 \\
(0.030)\end{array}$ & $\begin{array}{l}1.061 \\
(0.021)\end{array}$ & $\begin{array}{l}0.973 \\
(0.005)\end{array}$ \\
\hline$\hat{\mu}$ & $\begin{array}{l}1.201 \\
(0.008)\end{array}$ & $\begin{array}{l}1.120 \\
(0.007)\end{array}$ & - & $\begin{array}{l}1.284 \\
(0.033)\end{array}$ & $\begin{array}{l}1.109 \\
(0.016)\end{array}$ & - & $\begin{array}{l}1.258 \\
(0.029)\end{array}$ & $\begin{array}{l}1.091 \\
(0.014)\end{array}$ & - \\
\hline$\hat{\mu}^{W}$ & $\begin{array}{l}0.636 \\
(0.006)\end{array}$ & - & - & $\begin{array}{l}0.219 \\
(0.022)\end{array}$ & - & - & $\begin{array}{l}0.237 \\
(0.020)\end{array}$ & - & - \\
\hline$\hat{\phi}$ & $\begin{array}{l}0.482 \\
(0.001)\end{array}$ & - & - & $\begin{array}{l}0.244 \\
(0.001)\end{array}$ & - & - & $\begin{array}{l}0.191 \\
(0.024)\end{array}$ & - & - \\
\hline$\hat{\mu} / \hat{\theta}$ & 1.165 & 1.081 & - & 0.986 & 0.994 & - & 1.020 & 1.028 & - \\
\hline
\end{tabular}

Note: Standard errors in parentheses. Sample period 1989-2008; dependent variable: log. gross deflated output $y_{i t}$.

The estimated structural parameters are retrieved as the following: $\hat{\theta}_{L}$ : sample mean of $\hat{\mu}\left(1-\hat{\mu}^{W}\right) s_{L t}^{j}$, $\hat{\theta}_{M}=\hat{\mu} \hat{\gamma}_{M}, \hat{\theta}_{K}=\hat{\mu} \hat{\gamma}_{K}, \hat{\theta}=\hat{\theta}_{L}+\hat{\theta}_{M}+\hat{\theta}_{K}, \hat{\mu}=1 /\left(1+\frac{1}{\hat{\eta}}\right), \hat{\phi}$ : sample mean of $\frac{1}{\left(1+\Pi_{i t} / W_{i t} L_{i t} \hat{\mu}^{W}\right)}$.

$a: y_{i t}=\gamma_{0}+\gamma_{K} k_{i t}+\gamma_{M} m_{i t}+\left(1-\mu^{W}\right) s_{L t}^{j} l_{i t}-\frac{1}{\eta^{j}} q_{t}^{j}+\tilde{a}_{i t}+\tilde{\tilde{u}}_{i t}$.

$b: y_{i t}=\gamma_{0}+\gamma_{K} k_{i t}+\gamma_{M} m_{i t}+\gamma_{L} l_{i t}-\frac{1}{\eta^{j}} q_{t}^{j}+\tilde{a}_{i t}+\tilde{\tilde{u}}_{i t}$.

$c: y_{i t}=\gamma_{0}+\gamma_{K} k_{i t}+\gamma_{M} m_{i t}+\gamma_{L} l_{i t}+a_{i t}+u_{i t}$.

and De Loecker, 2011). Indeed, given that inputs and output are positively correlated and output and price are negatively correlated, we expect the correlation between inputs and firm-level price differences to be negative. These downward biases are significant for the labor and materials coefficients, but not statistically significant for the capital coefficient estimated using the control function approach (Wool.-LP). De Loecker (2011) also finds similar results. In general, the variation of the estimates of the capital coefficient when introducing the demand shifter is much smaller compared with the other input elasticities. Additionally, omitting the price variable leads to the underestimation of the scale elasticity. Our estimates of the production function are not always in line with those found in the literature. De Loecker (2011), using data from the Belgian textile industry, corrects for both simultaneity (using the Olley and Pakes's methodology) and omitted price bias estimates and finds the estimated output markup equal to 1.45 against our 1.09. Indeed, comparing his results with our column $b$ of Wooldridge's one-step efficient estimation of Levinsohn and Petrin (2003), we find much smaller production function coefficients (also smaller standard errors) and output markup. De Loecker (2011) finds the input elasticities of labor, materials, and capital equal to 0.307, 0.906, and 0.150, respectively 14

Dobbelaere and Mairesse (2013), with a first-difference OLS estimation of a production

\footnotetext{
${ }^{14}$ The standard errors of a nonlinear combination of the estimated coefficients are computed using the Delta method.
} 
function featuring an efficient bargaining in the labor market, find decreasing returns to scale (0.792) versus our slightly increasing but significant scale elasticity (1.031, column $a$ of the within estimator). On the other hand the labor and capital elasticities are of approximately the same small magnitude. Their output markup is equal to 1.102 , while with our data on the Dutch manufacturing industry, we find this to be larger (1.201). The bargaining parameter found by Dobbelaere and Mairesse (2013) with the OLS estimator is much larger (0.552) than what Dobbelaere (2004) and we find. with the Arellano and Bond (1991) and IV estimators, respectively. Indeed, the bargaining elasticity is equal to 0.482 (within estimator), while with the IV estimator we find a bargaining power of 0.244, which coincides with what Dobbelaere (2004) finds. Dobbelaere and Mairesse (2013) also perform a Blundell and Bond (2000) estimation of the production function. Under this estimation approach, Dobbelaere and Mairesse (2013) still find a low estimate of the capital elasticity and slightly decreasing returns to scale (0.033 and 0.969 , respectively). Column $a$ of the IV estimation reports capital and scale elasticities of 0.080 and 1.301, respectively. On the other hand, the output markup and bargaining parameter are much larger than what we find. The markup is equal to 1.383 against our 1.284; the estimated bargaining parameter is 0.552 , while we find this to be equal to 0.244. However, the results of Dobbelaere (2004) for Belgian data are somewhat inconsistent with the results of Dobbelaere and Mairesse (2013), who use French data. The union's bargaining power parameter, according to McDonald and Suen's (1992) framework, is positively dependent on the ratio between the trade union density 15 and the unemployment rate. As this ratio is, at the aggregate level, higher for Belgium than for France (roughly, 6.2 and 0.9, respectively; source: OECD Labour Force Statistics), one would expect to find higher bargaining power in Belgium than in France. On the other hand, the Netherlands report a trade union density/unemployment rate ratio of approximately 4 . We would then expect to find a somewhat smaller bargaining coefficient, rather than the exact same magnitude (if not larger, as we move to the control function approach estimates). We find consistent results with the (weighted) average of the workers' power parameters over sectors. Indeed, except for the within estimator, we find bargaining elasticities ranging between 0.196 and 0.217 .

Along with the bargaining parameter, we are able to provide, within the production function framework, an estimate of the wage markup. We notice how the wage markup estimate is upward biased, when using the within estimator (63.6\%). When adopting a GMM framework, the wage markup fluctuates between $21.9 \%$ (IV) and 23.7\% (one-step Levinsohn and Petrin, 2003). These results are comparable with Aidt and Tzannatos's (2008) review of wage markups in high-income economies, which are between 0 and $25 \%$.

In addition to the parameters mentioned above, we also report the profit ratio parameter, which can be expressed as the estimated product markup divided by the estimated elasticity of scale, $\frac{\hat{\mu}}{\hat{\theta}}$. A profit ratio parameter larger than one indicates that the source

\footnotetext{
${ }^{15}$ Trade union density corresponds to the ratio of wage and salary earners that are trade union members, divided by the total number of wage and salary earners (OECD Labour Force Statistics).
} 
of profit lies either in imperfect competition rather than in decreasing returns to scale (Crépon et al., 2010).

\subsection{Across-Industry Estimates}

The nature of the underestimation discussed in Section 2.3 could be structural or computational. If structural, i.e., the workers tend to gain higher wage rents in those sectors where there is less competition, we expect to find a positive association between the wage markup $\mu^{W}$ and the output markup $\mu_{j}$ (see also equation (12) ). On the other hand, if the existing monopoly rents are eroded by some bargaining power of the workers' union, the bias derives from an underestimation of the true level of price-cost margins (Bughin, 1993) and we expect a negative correlation between the two parameters.

Given the evidence of sectoral specificity of capital and labon ${ }^{16}$ (Dosi. 1999: Ramey and Shapiro, 2001), we investigate the heterogeneity of the manufacturing industry, by studying across-industry firms' production behavior.

For each of the 21 sectors, we estimate equation (13) with and without the extension to labor imperfections (model specifications $a$ and $b$, respectively). Year dummies are always included. Moreover, the production index is constructed as in De Loecker (2011), by proxying the total demand for a six-digit sector $\tilde{j}$ with a (market share) weighted average of deflated revenue, $q_{j t}^{\tilde{j}}=\sum_{i}^{N_{\tilde{j}}} m s_{i t} y_{i t}$. Table 8.1 in Section 8 reports the within estimates of the relevant parameters, namely the output and wage markups, $\widehat{\mu}_{j}$ and $\widehat{\mu}^{W j}$, respectively, and the bargaining elasticities, $\widehat{\phi}^{j}$. Table 8.2 displays the IV estimated coefficients, while Table 8.3 reports the structural estimates obtained using the control function approach.

Testing the hypothesis of heterogeneity across sectors yields the conclusion that all the structural parameters statistically differ from sector to sector, and are sensitive to the estimation technique. This confirms the assumption of sectoral specificities. Each sector has its own functioning, and the firm belonging to a specific sector adopts a different production strategy compared to a firm in another sector.

Quite consistently with what we found for the whole manufacturing industry, excluding imperfections on the labor market leads to an underestimation of the markups for the majority of sectors. When assuming imperfect competition in the labor and in the output markets, the output market markups range from 0.940 (sector 27, metals) to 2.730 (sector 25 , rubber and plastic products) for the within estimator; from 0.899 (sector 19, textile and leather products) to 3.380 (sector 20, wood) for the IV estimator; from 0.869 (sector 19) to 3.446 in the manufacturing sector of wood (Wool.-LP estimator). On the other hand, when disregarding the possibility to have frictions on the labor market, the output price markups range from 0.857 (sector 27) to 1.439 (sector 25) for the within estimator; from 0.921 (sector 19) to 1.632 (sector 23, coke, petroleum and nuclear fuel) for the IV estimator; from 0.853 (sector 32) to 1.288 (sector 18) for the Wool.-LP estimator.

\footnotetext{
${ }^{16}$ The "social embeddedness" of firms' routines and strategies is likely to be driven by socially specific factors, such as the nature of the local labor markets, workforce training institutions, financial institutions. Furthermore, Ramev and Shapiro (2001) suggest significant sectoral specificity of physical capital and substantial costs of redeploying the capital.
} 
With every estimation technique, we find negative correlation between the parameters $\mu_{j}$ and the labor market friction parameters $\mu^{j W}$ and $\phi^{j}$. The Spearman's rank correlation coefficient becomes statistically significant as we perform an IV, or Wool.-LP. This confirms the hypothesis of a pure computational bias of the true level of the output markup $\mu_{j}$, possibly caused by the misspecification of the marginal costs, as we are omitting the direct effects of wage rigidities. Therefore, firms share their monopoly rents with labor unions. This result is in contrast with the findings of Dobbelaere (2004), Crépon et al. (2010), and Dobbelaere and Mairesse (2013) who find positive correlation. Dobbelaere (2004) interprets this positive correlation between labor bargaining and output market power as the effect of the exit of firms. In particular, she guesses that strong unions reduce the firms' share of rents, forcing some of the firms to exit the market, therefore decreasing the degree of market power. Another explanation she provides deals with the fact that stronger unions are attracted by those sectors where rents can be extracted.

Both these two interpretations have problems. The first interpretation builds on the premise of a static setting, which does not allow for the dynamic aspects of competition (such as the implications of selection bias and reallocation effects). The second interpretation concerns more the profitability of the firm, rather than its level of price-cost margin. A more profitable firm can attract workers that are able to extract some of the surplus. But a higher markup does not necessarily mean that the enterprise is profitable, as it does not take into account relative cost efficiencies (see Boone and van der Wiel, 2007, Boone, 2008, and Griffith et al., 2008, for a discussion on relative profits and relative cost efficiencies). Therefore, we tested the correlation between the wage markup and the relative profits measure (computed as in Boone and van der Wiel, 2007). We find that indeed these two measures, profit elasticity and union power, are positively correlated $(\rho=0.46$, significant at the $5 \%$ level. Results of the profit elasticities per sector are not reported, but available upon request.)

\section{Impact on TFPG}

In this paper we propose a measure of TFP growth (TFPG) derived from estimating a production function which accounts for imperfect competition in both output and labor markets as derived in Section 2. The TFP measure is computed as

$$
T F P_{i t}=\hat{a}_{i t} \equiv \hat{\mu}_{j}\left[y_{i t}-\left(\hat{\gamma}_{K} k_{i t}+\hat{\gamma}_{M} m_{i t}+\left(1-\hat{\mu}^{W}\right) s_{i L t} l_{i t}-\frac{1}{\hat{\eta}_{j}} q_{t}^{j}\right)\right] .
$$

To compute the TFP growth index, we follow De Loecker and Konings (2006) and take an employment based share weighted firm-level TFPG, where the shares are simply $\pi_{i t}^{j}=$ $L_{i t} / \sum_{i} L_{i t}^{j}$. We also derive a measure of TFPG following (26), allowing for the structural parameters to vary across sectors. Table 6.1 reports the weighted average TFPG percentage rates for every estimation approach and for all three specifications $(a, b$, and $c)$. We find that correcting for the omitted output prices, therefore taking into account the 
Table 6.1: Weighted average TFP growth rates for the entire manufacturing sector (1989-2008)

\begin{tabular}{lllll}
\hline & & $a$ & $b$ & $c$ \\
\hline \multirow{3}{*}{ Within } & $L \leq 50$ & 1.71 & 1.48 & 1.37 \\
& $L \leq 250$ & 1.34 & 0.83 & 0.90 \\
& $L>250$ & 1.52 & 1.13 & 1.11 \\
& avg & 1.27 & 0.86 & 0.88 \\
\cline { 2 - 4 }$I V$ & $L \leq 50$ & 2.13 & 1.08 & 1.00 \\
& $L \leq 250$ & 1.41 & 0.35 & 0.46 \\
& $L>250$ & 1.39 & 0.30 & 0.40 \\
avg & 1.73 & 0.67 & 0.70 \\
\cline { 2 - 4 } Wool. $-L P$ & $L \leq 50$ & 2.19 & 1.18 & 1.12 \\
& $L \leq 250$ & 1.57 & 0.54 & 0.62 \\
& $L>250$ & 1.57 & 0.51 & 0.58 \\
& avg & 1.85 & 0.83 & 0.84 \\
\hline
\end{tabular}

Note: $a: y_{i t}=\gamma_{0}+\gamma_{K} k_{i t}+\gamma_{M} m_{i t}+\left(1-\mu^{W}\right) s_{L t}^{j} l_{i t}-\frac{1}{\eta^{j}} q_{t}^{j}+\tilde{a}_{i t}+\tilde{\tilde{u}}_{i t}$.

$b: y_{i t}=\gamma_{0}+\gamma_{K} k_{i t}+\gamma_{M} m_{i t}+\gamma_{L} l_{i t}-\frac{1}{\eta^{j}} q_{t}^{j}+\tilde{a}_{i t}+\tilde{\tilde{u}}_{i t}$.

c: $y_{i t}=\gamma_{0}+\gamma_{K} k_{i t}+\gamma_{M} m_{i t}+\gamma_{L} l_{i t}+a_{i t}+u_{i t}$

Table 6.2: Weighted average TFP growth rates per sector

$T F P G(a)$

\begin{tabular}{lrrrr}
\hline sector & IV & Wool.-LP & IV & Wool.-LP \\
\hline 15 & 0.49 & 1.00 & -0.44 & 0.13 \\
17 & 1.09 & 0.81 & 1.11 & 0.80 \\
18 & 2.62 & 3.35 & 2.88 & 2.55 \\
19 & 3.16 & 2.23 & 1.27 & 1.02 \\
20 & 1.64 & 1.47 & -0.69 & -0.85 \\
21 & 0.69 & 0.87 & 0.39 & 0.53 \\
22 & 0.34 & 0.37 & 0.16 & 0.21 \\
23 & - & - & - \\
24 & 0.98 & 1.26 & 0.47 & 0.90 \\
25 & 1.99 & 2.15 & 1.76 & 1.29 \\
26 & 0.79 & 1.92 & 0.49 & 0.59 \\
27 & 1.39 & 2.74 & 0.80 & 1.03 \\
28 & 2.84 & 2.91 & 1.06 & 1.07 \\
29 & 3.24 & 5.75 & 1.00 & 0.91 \\
30 & 3.82 & 3.34 & 1.08 & 1.44 \\
31 & 3.13 & 3.64 & 1.72 & 1.62 \\
32 & 2.05 & 2.70 & 1.05 & 3.02 \\
33 & 2.70 & 1.14 & 1.05 \\
34 & 2.28 & 1.43 & 1.33 \\
35 & 3.83 & 3.40 & 0.32 & 1.29 \\
\hline $6 \mathrm{avg}$ & 1.12 & 0.80 & 1.28 & 0.15 \\
\hline & 1.90 & 1.91 & & 0.73 \\
\hline
\end{tabular}


possibility for the firms to set prices above their marginal costs, leads to decreases of the TFPG percentage rates of $2.3 \%$ (within), $4.5 \%$ (IV), and $1.2 \%$ (Wool.-LP). Independently from the estimation technique used, when assuming both bargaining on the labor market and imperfect competition on the output market, we find larger TFPG rates (column a). In particular, with the within estimator we find a $47.6 \%$ higher TFPG rate than the TFPG rate estimated under the sole assumption of imperfect competition on the product market. With the IV, and the Wool.-LP, we find $158.2 \%$ and $122.8 \%$ higher TFPG rates, respectively. Moreover, the size of the firm, measured as the number of employees, seems to be negatively correlated with the TFPG rates when using the IV or control function approaches. In particular, we find that firms with less than 50 employees are the most productive ones.

Differently from the findings of Dobbelaere and Vancauteren (2014), our results show systematic higher TFP growth rates under imperfect competition in both output and labor markets (ranging from $1.27 \%$ to $1.85 \%$, see Table 6.1) relatively to a setting where there is only imperfect competition in the output market. In Dobbelaere and Vancauteren (2014) negligible differences are found between both regime types using data on Dutch and Belgian manufacturing firms. The explanation of this could be attributed to a different model specification and a different econometric methodology.

Figure 1 reports the three time series of the TFPG rates under the three different market structure assumptions (imperfect competition on both output and labor markets, $a$, imperfect competition on the output market, $b$, and perfect competition, $c$ ). Each panel reports the TFPG index under the three different estimation strategies.

The first feature of the estimates of the firms' average productivity growth when assuming imperfect competition on both markets is its larger variance, with growth rates ranging from $-3.96 \%$ to $9.95 \%$ (IV estimation approach). Indeed, when considering the model specification $b$ or $c$, we find ranges of values between $-1.09 \%$ and $3.07 \%$, which are in line with the TFPG rated reported by the OECD 17 for the Dutch manufacturing sector. Moreover, with each estimation approach we find evidence of a positive time trend only when we consider both labor and product market imperfections.

Table 6.3: Correlation between TFP growth and structural parameters

\begin{tabular}{lll}
\hline$\rho$ & TFPG(IV) & TFPG(Wool.-LP) \\
\hline$\mu_{j}$ & -0.0833 & 0.0857 \\
$\mu^{j W}$ & -0.0195 & 0.0779 \\
$\phi^{j}$ & 0.1519 & 0.1636 \\
\hline
\end{tabular}

Table 6.2 reports the percentage growth rates estimated using IV and the Wool.LP approach for the functional assumptions $a$ and $b$. We confront these two estimation approaches as we want to investigate the consequences of allowing the productivity to be

\footnotetext{
${ }^{17}$ http://www.oecd.org/statistics/productivity.
} 
distributed as an $\mathrm{AR}(1)$ process. As one can see, when assuming wage premia and price markups (model $a$ ), omitting or including the dynamics of the productivity process (IV or Wool.-LP) does not make a difference in the TFPG rates, on average. On the other hand, when assuming only product imperfect competition, the Levinsohn and Petrin (2003) estimator yields much lower growth rates. Looking at the first two columns of the table, we see that the sectors that display very high TFPG rates (around 3\%) wi are textile and leather products, metal products, machinery and equipment, and transport equipment. Sectors that have a TFPG rate between $2 \%$ and $3 \%$ are rubber and plastic products, electrical and optical equipment, and transport equipment 18

Table 6.3 displays the Spearman correlation coefficients between TFPG rates and the structural parameters describing the imperfect competition on the labor and on the output market. When considering the possibility of a first-order Markov productivity process, the weighted average productivity growth rate seems to be positively associated with both labor market frictions parameters, and with the output price mark-ups; while with the IV estimation of the TFPG, we find a negative correlation between productivity growth, output, and wage markups.

Figure 2 plots the TFPG rates obtained from the two estimation approaches (IV and Wool.-LP) against the workers bargaining parameter $\phi^{j}$ for each sector. It is easy to detect the positive correlation between the productivity growth and the bargaining parameter in the second plot. The economic benefits of unions could be found in the worker-manager cooperation. Indeed, unions can increase firms' productivity by "shocking" the management into better production practices (Aidt and Tzannatos, 2008). Masayuki and Morikawa (2010) empirically analyze the relationship between labor union and firm performance by using data on 4000 Japanese firms in both the manufacturing and non-manufacturing sectors. The presence of labor unions has statistically and economically significant positive effects on firm productivity. Indeed unions may enhance productivity when these contribute to the strengthening of the firm's competitiveness, by fostering cooperation between labor and management.

\section{Conclusion}

We examine the relationship between productivity growth, monopolistic market power of firms, and the wage bargaining power of workers using firm-level data on 21 Dutch manufacturing sectors for the period 1989-2008. Our study contributes to several strands of literatures. First, it derives a measure of wage markup without relying on trade union participation data. Typically, the literature on productivity and trade unions relies on sector-level data (Brown and Medoff, 1978) or measures the productivity differences between unionized versus non-unionized firms (Morikawa, 2010), without endogenizing the presence of labor unions. This paper, similarly to other studies that simultaneously consider imperfections in the product and the labor market (Bughin, 1996; Dobbelaere, 2004;

\footnotetext{
${ }^{18}$ For the corresponding NACE codes of the sectors, see Table 8.4
} 
Abraham et al., 2009; Dobbelaere and Mairesse, 2013; Dobbelaere and Vancauteren, 2014), examines a monopolistic framework which accounts for wage bargaining. In addition to the other studies, along with the parameters characterizing the production function and the price-cost margins, we derive a measure of wage markup, and we study the correlation of the estimated parameters and markups with the firm-level productivity growth.

Second, the paper contributes to literature on the structural identification of production functions (Ackerberg et al., 2006; Wooldridge, 2009) in two ways. As a first step, it reviews the different estimation techniques that have been tackling the endogeneity issues concerning the simultaneity, the omitted output price, and the collinearity among factors of production. Then, the study proposes an identification strategy that relies on the presence of imperfect competition in the flexible input market, namely, the labor market.

We show that, neglecting a wage markup leads to an underestimation of the value of the price-cost margin at the aggregate level. Depending on the estimation approach, the underestimation of the product markups varies between $7 \%$ and $16 \%$. The workers' bargaining power parameters range between 0.191 and 0.482 . These results, except for the within estimator, are consistent with the trade union density/unemployment rate ratio reported for the Netherlands. Along with the bargaining parameter, we estimate the wage markup. The wage markup estimates fluctuates between $21.9 \%$ and $23.7 \%$. These results are comparable with Aidt and Tzannatos's (2008) review of wage markups in high-income economies, which are between 0 and $25 \%$.

In line with the literature, we find that omitting output prices yields downward biased input elasticity coefficients. We then confirm the hypothesis of sectoral specificity as suggested by Ramey and Shapiro (2001), namely, sectoral specificity concerning physical capital, which is costly to redeploy, sectoral nature of the local labor markets, workforce training institutions, and financial institutions. Indeed, testing the hypothesis of heterogeneity across sectors yields the conclusion that all the structural parameters significantly differ from sector to sector, and are sensitive to the estimation technique.

Moreover, we find that the underestimation of the product markups derives from a computational bias of the true level of the output markup, possibly caused by the misspecification of the marginal costs, as we are omitting the direct effects of wage rigidities. Therefore, firms share their monopoly rents with labor unions.

Concerning the impact of different estimation approaches and model assumptions on the firm-level productivity, with each estimation approach, we find evidence of a positive time trend only when we consider both labor and product market imperfections.

We find that correcting for the omitted output prices leads to decreases of the TFPG percentage rates, and, independently from the estimation technique used, when assuming both bargaining on the labor market and imperfect competition on the output market, we find larger TFPG rates. With both IV and Levinsohn and Petrin (2003) estimation of the TFP growth we find a significant and positive relation between productivity growth and the bargaining parameter. The economic benefits of unions could be found in the workermanager cooperation. Indeed, unions can increase firms' productivity by "shocking" the 
management into better production practices (Aidt and Tzannatos, 2008).

A potential drawback of our and the related analyses is the adoption of a static framework. In fact, when assuming an imperfect labor market, the likely presence of adjustment costs (Bond and Söderbom, 2005), calls for the adoption of a dynamic optimization framework to account for costs of adjusting capital and labor. We leave this as a possible extension and topic for future research. 


\section{References}

Abraham F, Konings J, Vanormelingen S. 2009. The effect of globalization on union bargaining and price-cost margins of firms. Review of World Economics (Weltwirtschaftliches Archiv) 145: 13-36.

Ackerberg D, Benkard L, Berry S, Pakes A. 2007. Econometric Tools for Analyzing Market Outcomes. Handbook of Econometrics 6.

Ackerberg D, Caves K, Frazer G. 2006. Structural Identification of Production Functions. Technical report, UCLA mimeo.

Aidt TS, Tzannatos Z. 2008. Trade unions, collective bargaining and macroeconomic performance: a review. Industrial Relations Journal 39: 258-295. ISSN 1468-2338.

Arellano M, Bond S. 1991. Some tests of specification for panel data: Monte carlo evidence and an application to employment equations. Review of Economic Studies 58: 277-97.

Blundell R, Bond S. 2000. Gmm estimation with persistent panel data: an application to production functions. Econometric Reviews 19: 321-340.

Bond S, Söderbom M. 2005. Adjustment costs and the identification of cobb douglas production functions. Economics Papers 2005-W04, Economics Group, Nuffield College, University of Oxford.

URL http://ideas.repec.org/p/nuf/econwp/0504.html

Boone J. 2008. A new way to measure competition. The Economic Journal 118: 12451261.

Boone J, van der Wiel H. 2007. How (not) to measure competition. CPB Discussion Paper 91, CPB Netherlands Bureau for Economic Policy Analysis.

Brown C, Medoff J. 1978. Trade unions in the production process. Journal of Political Economy 86: pp. 355-378. ISSN 00223808.

URL http://www . jstor .org/stable/1833158

Bryan LL. 2007. The new metrics of corporate performance : profit per employee. The McKinsey quarterly : 57-65.

Bughin J. 1993. Union-firm efficient bargaining and test of oligopolistic conduct. The Review of Economics and Statistics 75: 563-567.

Bughin J. 1996. Trade unions and firms' product market power. The Journal of Industrial Economics 44: pp. 289-307.

Cooper RW, Haltiwanger JC. 2006. On the nature of capital adjustment costs. The Review of Economic Studies 73: pp. 611-633. ISSN 00346527.

URL http://www . jstor .org/stable/20185022 
Crépon B, Desplatz R, Mairesse J. 2010. Price-Cost Margins and Rent Sharing: Evidence from a Panel of French Manufacturing Firms. Annales D'conomie et de Statistique, 79-80, July-December 2005, 583-610.

URL http://www.nber .org/chapters/c12247

De Loecker J. 2011. Product differentiation, multiproduct firms, and estimating the impact of trade liberalization on productivity. Econometrica 79: 1407-1451. ISSN 1468-0262.

De Loecker J, Konings J. 2006. Job reallocation and productivity growth in a post-socialist economy: Evidence from slovenian manufacturing. European Journal of Political Economy 22: 388-408.

Dobbelaere S. 2004. Estimation of price-cost margins and union bargaining power for belgian manufacturing. International Journal of Industrial Organization 22: 13811398 .

Dobbelaere S, Mairesse J. 2013. Panel data estimates of the production function and product and labor market imperfections. Journal of Applied Econometrics 28: 1-46.

Dobbelaere S, Vancauteren M. 2014. Market imperfections, skills and total factor productivity : Firm-level evidence on Belgium and the Netherlands. Working Paper Research 267, National Bank of Belgium.

URL http://ideas.repec.org/p/nbb/reswpp/201410-267.html

Dosi G. 1999. Innovation Policy in a Global Economy, chapter Some Notes on National Systems of Innovation and Production, and their Implications for Economic Analysis. Cambridge University Press.

Foster L, Haltiwanger J, Syverson C. 2008. Reallocation, firm turnover, and efficiency: Selection on productivity or profitability? American Economic Review 98: 394-425.

Galí J, Gertler M, Lpez-Salido JD. 2007. Markups, gaps, and the welfare costs of business fluctuations. The Review of Economics and Statistics 89: 44-59.

Gandhi A, Navarro S, Rivers D. 2011. On the identification of production functions: How heterogeneous is productivity? University of Western Ontario, CIBC Centre for Human Capital and Productivity Working Papers 20119, University of Western Ontario, CIBC Centre for Human Capital and Productivity.

URL http://ideas.repec.org/p/uwo/hcuwoc/20119.html

Griffith R, Boone J, Harrison R. 2008. Measuring competition. Social Science Research Network Working Paper Series .

URL http://ssrn. com/abstract=1307004

Hall RE. 1986. Market structure and macroeconomic fluctuations. Brookings Papers on Economic Activity 17: 285-338. 
Hall RE. 1988. The relation between price and marginal cost in u.s. industry. Journal of Political Economy 96: 921-47.

Hall RE. 1991. Invariance properties of solow's productivity residual. Working Paper 3034, National Bureau of Economic Research.

Katayama H, Lu S, Tybout JR. 2009. Firm-level productivity studies: Illusions and a solution. International Journal of Industrial Organization 27: 403-413.

URL http://ideas.repec.org/a/eee/indorg/v27y2009i3p403-413.html

Klette TJ, Griliches Z. 1996. The inconsistency of common scale estimators when output prices are unobserved and endogenous. Journal of Applied Econometrics 11: 343-61.

Levinsohn J, Petrin A. 2003. Estimating production functions using inputs to control for unobservables. Review of Economic Studies 70: 317-341.

Masayuki, Morikawa. 2010. Labor unions and productivity: An empirical analysis using japanese firm-level data. Labour Economics 17: 1030 - 1037.

McDonald IM, Solow RM. 1981. Wage bargaining and employment. American Economic Review 71: 896-908.

McDonald IM, Suen A. 1992. On the measurement and determination of trade union power. Oxford Bulletin of Economics and Statistics 54: 209-24.

URL http://ideas.repec.org/a/bla/obuest/v54y1992i2p209-24.html

Morikawa M. 2010. Labor unions and productivity: An empirical analysis using japanese firm-level data. Labour Economics 17: 1030 - 1037. ISSN 0927-5371.

URL http://www.sciencedirect.com/science/article/pii/S092753711000031X

Olley GS, Pakes A. 1996. The dynamics of productivity in the telecommunications equipment industry. Econometrica 64: pp. 1263-1297.

Ornaghi C. 2008. Price deflators and the estimation of the production function. Economics Letters 99: 168 - 171. ISSN 0165-1765.

Ramey VA, Shapiro MD. 2001. Displaced capital: A study of aerospace plant closings. Journal of Political Economy 109: pp. 958-992.

Wooldridge JM. 2009. On estimating firm-level production functions using proxy variables to control for unobservables. Economics Letters 104: 112-114. 


\section{Additional tables and figures}

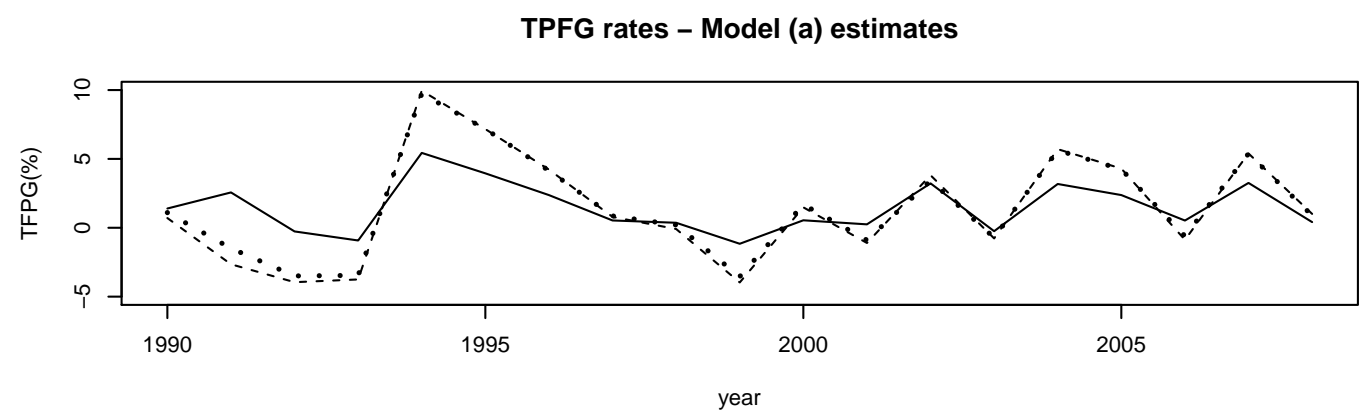

Model (b) estimates

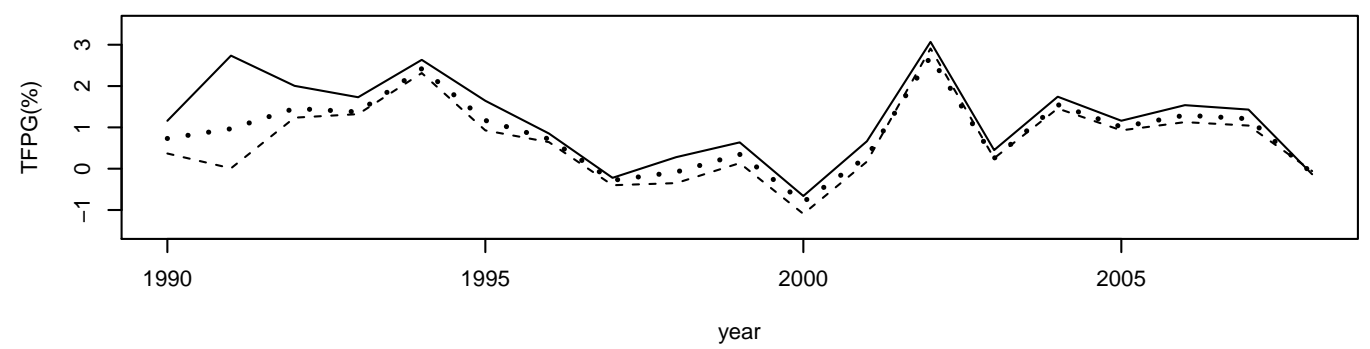

Model (c) estimates

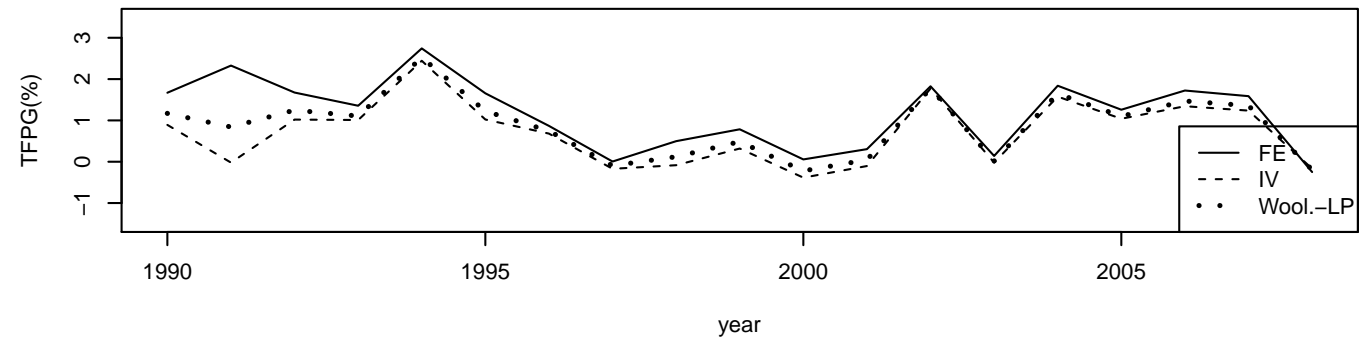

Note: Sample period 1989-2008; dependent variable: log. gross deflated output $y_{i t}$

$T F P G_{i t}=\pi_{i t}^{j} \Delta \hat{a}_{i t} \equiv \pi_{i t}^{j} \Delta\left[\hat{\mu}_{i t}\left(y_{i t}-\left(\hat{\gamma}_{K} k_{i t}+\hat{\gamma}_{M} m_{i t}+\left(1-\hat{\mu}^{W}\right) s_{i t} l_{i t}-\frac{1}{\eta^{j}} q_{t}^{j}\right)\right)\right]$, where $\pi_{i t}^{j}=L_{i t} / \sum_{i} L_{i t}^{j}$

Figure 1: TFP Growth by estimation approach 


\section{IV estimates}

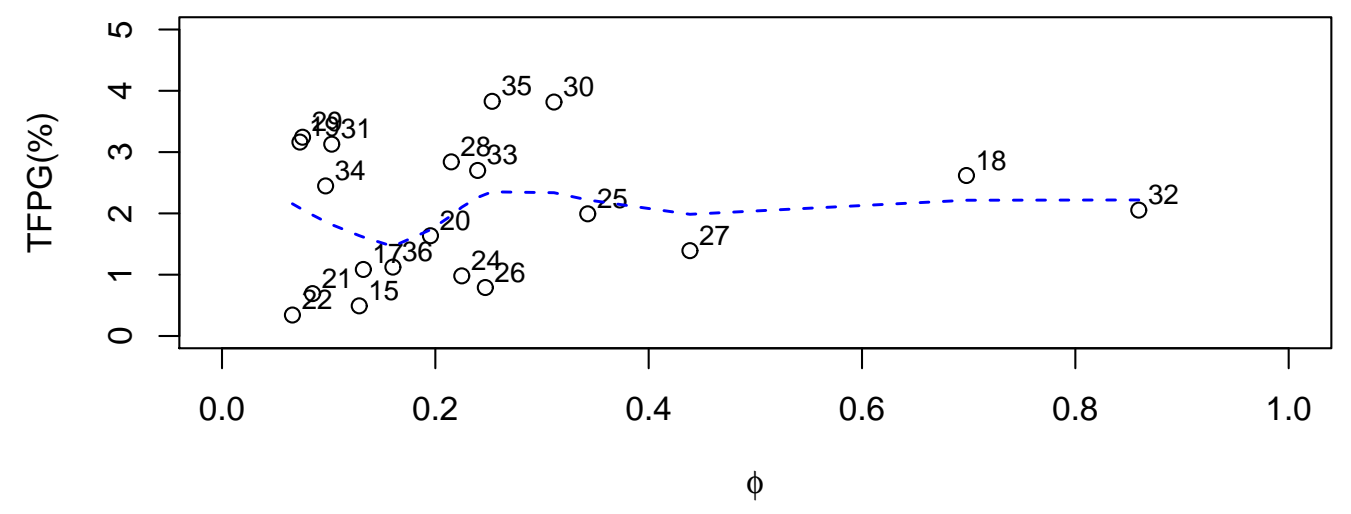

Wooldridge-LP estimates

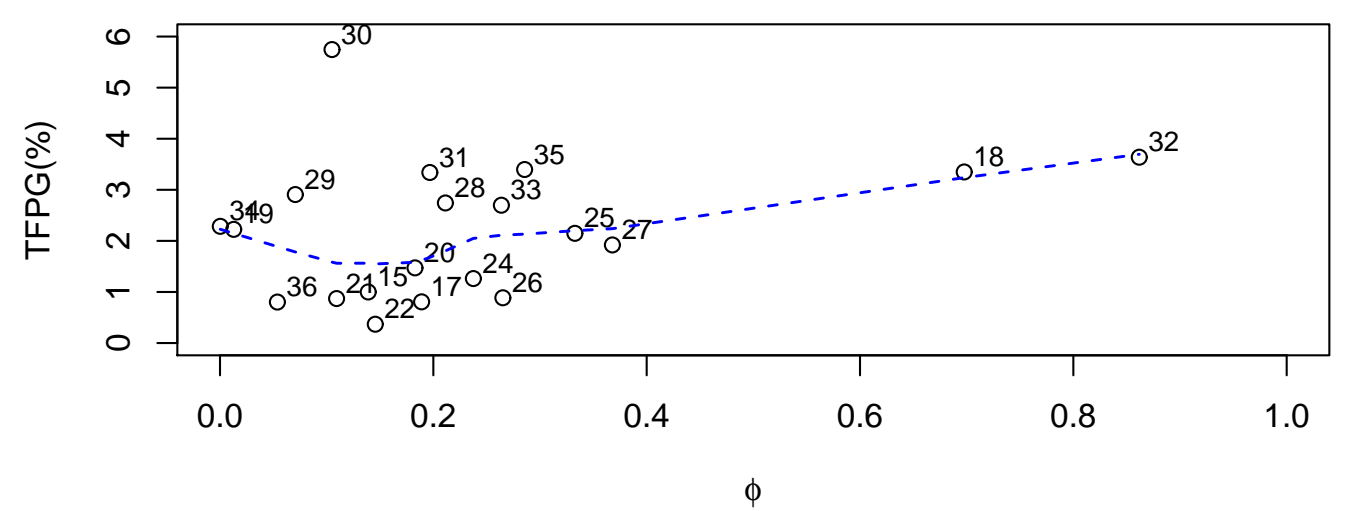

Note: Weighted average TFPG over the period 1990-2008 from model $a$ (labor and market imperfections).

Figure 2: TFP Growth per sector 
Table 8.1: Within estimates of $\mu_{j}, \mu_{i t}^{W}$ and $\phi_{i t}$ for 21 sectors

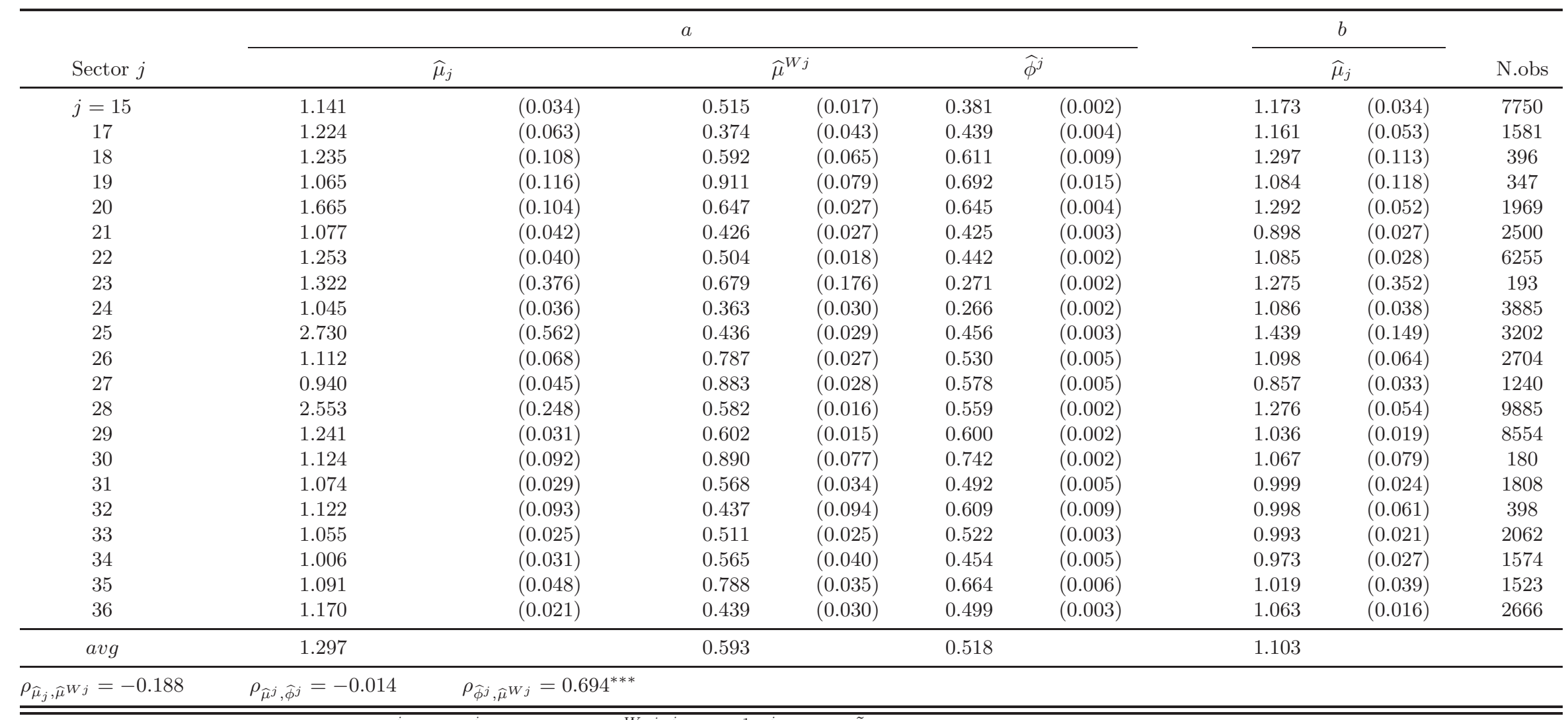

Note: Estimating equation: $y_{i t}=\gamma_{0}+\gamma_{K}^{j} k_{i t}+\gamma_{M}^{j} m_{i t}+\left(1-m u^{W}\right)^{j} s_{L t}^{j} l_{i t}-\frac{1}{\eta_{j}} q_{t}^{j}+\tilde{a}_{i t}+\tilde{u}_{i t}$.

Standard errors in parentheses; sample period 1989-2008. 
Table 8.2: IV estimates of $\mu, \mu_{i t}^{W}$ and $\phi_{i t}$ for 21 sectors

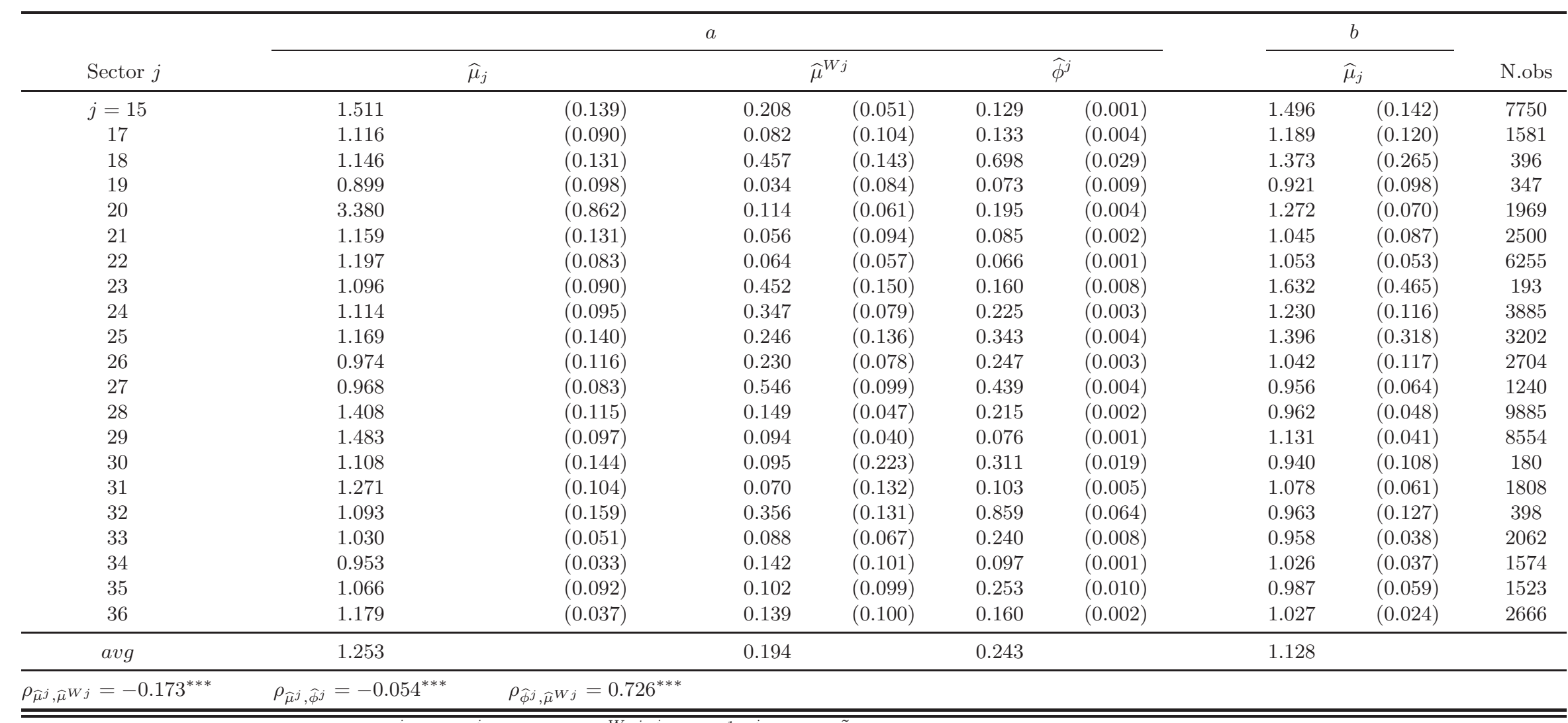

Note: Estimating equation: $y_{i t}=\gamma_{0}+\gamma_{K}^{j} k_{i t}+\gamma_{M}^{j} m_{i t}+\left(1-\mu^{W}\right)^{j} s_{L t}^{j} l_{i t}-\frac{1}{\eta^{j}} q_{t}^{j}+\tilde{a}_{i t}+\tilde{\tilde{u}}_{i t}$.

Standard errors in parentheses; sample period 1989-2008. 
Table 8.3: Wool.-LP estimates of $\mu, \mu_{i t}^{W}$ and $\phi_{i t}$ for 21 sectors

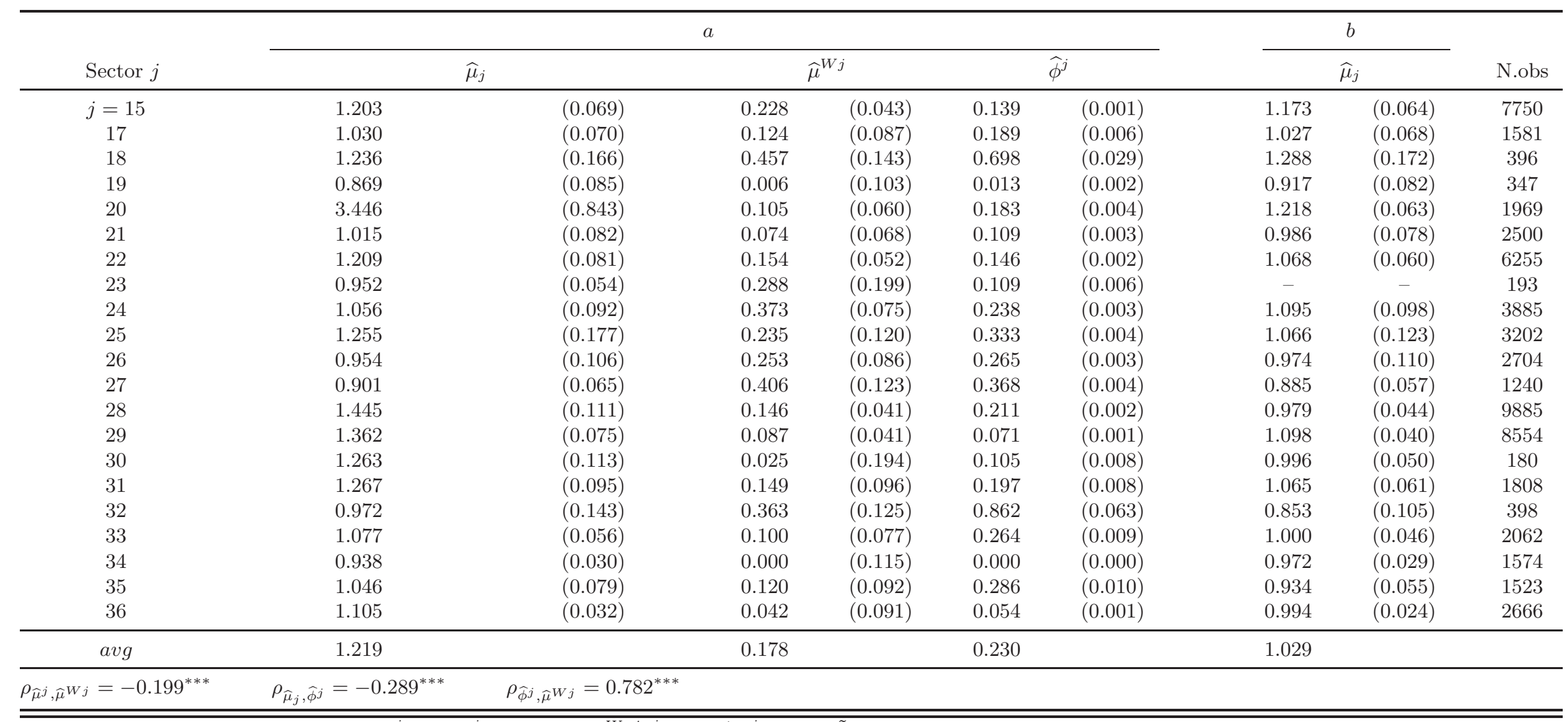

Note: Estimating equation: $y_{i t}=\gamma_{0}+\gamma_{K}^{j} k_{i t}+\gamma_{M}^{j} m_{i t}+\left(1-\mu^{W}\right)^{j} s_{L t}^{j} l_{i t}-\frac{1}{\eta^{j}} q_{t}^{j}+\tilde{a}_{i t}+\tilde{\tilde{u}}_{i t}$.

Standard errors in parentheses; sample period 1989-2008. 
Table 8.4: Averages per NACE two-digit sector code

\begin{tabular}{|c|c|c|c|c|c|c|c|c|c|}
\hline Sector & $y_{i t}$ & $l_{i t}$ & $m_{i t}$ & $k_{i t}$ & $s_{i L t}$ & $s_{i M t}$ & $s_{i K t}$ & $Q_{t}^{J}$ & N.obs.(N.firms) \\
\hline 15 & 9.311 & 4.185 & 8.904 & 6.089 & 0.200 & 0.688 & 0.055 & 0.991 & $7750(884)$ \\
\hline 17 & 8.817 & 4.037 & 8.254 & 5.562 & 0.273 & 0.618 & 0.043 & 1.047 & $1581(160)$ \\
\hline 18 & 7.931 & 3.464 & 7.325 & 4.150 & 0.294 & 0.596 & 0.029 & 1.297 & $396(56)$ \\
\hline 19 & 7.387 & 2.914 & 6.803 & 3.885 & 0.256 & 0.596 & 0.034 & 0.955 & $347(62)$ \\
\hline 20 & 8.609 & 3.890 & 8.204 & 5.157 & 0.264 & 0.651 & 0.033 & 0.911 & $1969(219)$ \\
\hline 21 & 9.468 & 4.437 & 9.002 & 6.562 & 0.241 & 0.633 & 0.058 & 0.929 & $2500(203)$ \\
\hline 22 & 8.522 & 3.821 & 7.921 & 5.457 & 0.312 & 0.560 & 0.056 & 1.032 & $6255(774)$ \\
\hline 23 & 10.264 & 4.566 & 9.820 & 7.598 & 0.129 & 0.735 & 0.060 & 1.059 & $193(23)$ \\
\hline 24 & 9.741 & 4.362 & 9.214 & 6.630 & 0.192 & 0.669 & 0.052 & 1.004 & $3885(419)$ \\
\hline 25 & 9.166 & 4.217 & 8.654 & 6.123 & 0.245 & 0.631 & 0.055 & 0.907 & $3202(321)$ \\
\hline 26 & 8.974 & 3.989 & 8.401 & 5.955 & 0.247 & 0.599 & 0.057 & 0.947 & $2704(275)$ \\
\hline 27 & 9.284 & 4.310 & 8.764 & 6.069 & 0.244 & 0.643 & 0.046 & 0.947 & $1240(125)$ \\
\hline 28 & 8.548 & 3.886 & 7.974 & 5.113 & 0.300 & 0.588 & 0.041 & 0.886 & $9885(1116)$ \\
\hline 29 & 8.853 & 4.110 & 8.306 & 5.283 & 0.303 & 0.595 & 0.033 & 0.881 & $8554(907)$ \\
\hline 30 & 9.396 & 4.428 & 8.895 & 5.375 & 0.286 & 0.634 & 0.034 & 1.128 & $180(23)$ \\
\hline 31 & 8.729 & 3.939 & 8.141 & 5.030 & 0.289 & 0.597 & 0.031 & 1.045 & $1808(211)$ \\
\hline 32 & 8.451 & 3.758 & 7.811 & 4.991 & 0.301 & 0.583 & 0.050 & 1.013 & $398(74)$ \\
\hline 33 & 8.454 & 3.905 & 7.692 & 4.874 & 0.356 & 0.514 & 0.037 & 1.040 & $2062(269)$ \\
\hline 34 & 9.009 & 4.174 & 8.576 & 5.240 & 0.248 & 0.670 & 0.029 & 0.932 & $1574(163)$ \\
\hline 35 & 8.889 & 4.013 & 8.395 & 4.900 & 0.270 & 0.643 & 0.026 & 0.922 & $1523(187)$ \\
\hline 36 & 8.476 & 3.918 & 7.931 & 5.003 & 0.301 & 0.603 & 0.035 & 0.944 & $2666(305)$ \\
\hline Total & 8.892 & 4.046 & 8.358 & 5.555 & 0.270 & 0.615 & 0.044 & 0.953 & $60672(6727)$ \\
\hline
\end{tabular}

(17-19); wood (20); paper, paper products, publishing and printing (21-22); coke, refined petroleum products and nuclear fuel (23); chemicals and chemical products

(24); rubber and plastic products (25); other non-metallic mineral products (26); basis metals and fabricated metal products (27-28); machinery and equipment n.e.c.

(29); electrical and optical equipment (30-33); transport equipment (34-35); other manufacturing activities (36). 